NBER WORKING PAPER SERIES

\title{
CAN TODAY'S AND TOMORROW'S WORLD UNIFORMLY GAIN FROM CARBON TAXATION?
}

\author{
Laurence J. Kotlikoff \\ Felix Kubler \\ Andrey Polbin \\ Simon Scheidegger \\ Working Paper 29224 \\ http://www.nber.org/papers/w29224 \\ NATIONAL BUREAU OF ECONOMIC RESEARCH \\ 1050 Massachusetts Avenue \\ Cambridge, MA 02138
}

September 2021, Revised April 2022

We thank Doris Folini for very useful conversations, and Florence Hugard and Malik Lechekhab for excellent research assistance, as well as Florian Oswald and seminar participants at the University of Lausanne and E4S for useful comments. We thank the Swiss National Science Foundation (SNF), under project ID "Can Economic Policy Mitigate Climate-Change?", and the Russian Science Foundation, under project No. 21-18-00126, for research support. The views expressed herein are those of the authors and do not necessarily reflect the views of the National Bureau of Economic Research.

NBER working papers are circulated for discussion and comment purposes. They have not been peer-reviewed or been subject to the review by the NBER Board of Directors that accompanies official NBER publications.

(C) 2021 by Laurence J. Kotlikoff, Felix Kubler, Andrey Polbin, and Simon Scheidegger. All rights reserved. Short sections of text, not to exceed two paragraphs, may be quoted without explicit permission provided that full credit, including $\odot$ notice, is given to the source. 
Can Today's and Tomorrow's World Uniformly Gain from Carbon Taxation?

Laurence J. Kotlikoff, Felix Kubler, Andrey Polbin, and Simon Scheidegger

NBER Working Paper No. 29224

September 2021, Revised April 2022

JEL No. H23,O44

\begin{abstract}
Climate change will impact current and future generations in different regions very differently. This paper develops the first large-scale, annually calibrated, multi-region, overlapping generations model of climate change and carbon policy. It features region-specific temperature and damage functions with the phased impact of emissions on global and regional temperature calibrated to the latest scientific evidence. Absent policy, calibrated worst-case damages in the next 200 years reach and remain near 20 percent of GDP for most regions, with India, Brazil, and the South Asian Pacific suffering roughly 40 percent of GDP losses. Russia and Canada benefit somewhat from global warming. Carbon taxation, coupled with region- and generation-specific transfers, can both correct the carbon externality and raise the welfare of all current and future agents across all regions by 4.3 percent. The impact on the use and duration of fossil fuels is dramatic, as is the reduction in the path of global emissions. However, achieving completely uniform welfare gains leaves future generations in particular regions with exceptionally high net taxes. Fortunately, a carbon tax-cum redistribution policy that limits the consumption-equivalent net tax burden on any generation in any region to less than 10 percent can deliver a 4.0 percent or higher welfare gain for all peoplekind - present and future. However, carbon taxes set through time, at carbon's marginal intertemporal social cost do far too little to mitigate climate change unless all major emitters, particularly China, adopt them and do so immediately.

Laurence J. Kotlikoff

Department of Economics

Boston University

270 Bay State Road

Boston, MA 02215

and NBER

kotlikoff@gmail.com

Felix Kubler

University of Zurich

Plattenstrasse 32

CH-8032 Zurich

Switzerland

and Swiss Financial Institute

fkubler@gmail.com

Andrey Polbin

The Russian Presidential Academy

of National Economy

and Public Administration

82 Vernadskogo prosp 117517

Moscow Russian Federation

and The Gaidar Institute for Economic Policy

apolbin@gmail.com

Simon Scheidegger

University of Lausanne

Department of Economics

Internef 509

CH-1015 Lausanne

Switzerland

simon.scheidegger@gmail.com
\end{abstract}




\section{Introduction}

Our problems are man-made; therefore, they can be solved by man. These inspiring words by President Kennedy apply in full measure to anthropogenic climate change with its massive projected damages - arguably humankind's worst externality. This paper derives Pareto-improving carbon policies, each implemented via a) an annual global carbon tax set at carbon's marginal intertemporal global damage, the so-called Social Cost of Carbon (SCC), and b) region- and generation-specific redistribution implemented via lump-sum taxes and transfers. There is, of course, a continuum of externality-correcting Pareto policies that differ in terms of the allocation of efficiency gains. We focus on three such policies: The first is a uniform welfare improving (UWI) policy. It delivers all humankind, regardless of time or place of birth, the highest uniform percentage welfare gain available from resolving the carbon externality. The second provides a UWI gain, but only for future generations (UWIF). Current generations are held at their business-as-usual (BAU, i.e., no policy) utility levels. The third policy we study is denoted as UWIL and provides a uniform welfare gain to each current and future region-specific cohort subject to the proviso that no cohort faces a redistribution tax of more than 10 percent of lifetime consumption. Those cohorts whose redistributive tax is limited enjoy a larger welfare gain than cohorts whose net tax is below the ceiling.

To calculate our three Pareto policies, we develop the first (to the best of our knowledge) large-scale (annually calibrated), multi-region, integrated assessment (IAM), overlapping generations (OLG) model. Our model features 18 regions inhabited by 80 overlapping, self-interested generations. Output is produced with capital, labor, and a time-varying combination of dirty and clean energy. Dirty energy comprises oil, gas, and coal, each of whose extraction is subject to increasing costs. Clean energy is produced with capital, labor, and a fixed factor that proxies for regional limits on green-energy production. The model's climate emulator ${ }^{1}-$ the equations connecting carbon emissions to atmospheric carbon concentration to the mean global temperature - is calibrated based on the latest climate science.

Background. As with other externalities, climate change reflects market failure. In this case, there are no cross-region, let alone cross-generation markets for agents to buy or sell abatement. That is the downside. The upside is that correcting the externality permits a continuum of Pareto improvements - efficiency gains that can be allocated to all or some segment of humankind. Identifying the Pareto frontier is a standard operating procedure in analyzing externality problems. It dates to Pigou (1920)'s path-breaking work. However, starting with Nordhaus (1979), climate-change modelers have posited a social planner with no concern with the status-quo (i.e., BAU) welfare distribution and, consequently, no inherent interest in Pareto improvements. This framework begs the question of which social planner with which degree of intergenerational altruism, as captured by the planner's time preference rate, to invoke.

Much of the more recent optimal carbon-tax literature (see, e.g., Golosov et al. (2014)) emulates the social-planner framework by positing infinitely-lived dynasties. Each dynasty comprises altruistically linked agents with typically one such agent alive at a point in time, hence, the nickname single-agent model. The single-agent framework begs the question of the single-

\footnotetext{
${ }^{1}$ Simplified and computationally cheap-to-evaluate climate models come at different levels of complexity (and computational costs) and under different names: climate emulators, energy balance models, or simple climate models. We avoid using this differentiation throughout this paper and, somewhat loosely, just use climate emulator or climate model.
} 
agent's time preference rate, which controls the intergenerationally altruistic economy's regard for current versus future dynasty members. As in the planner setup, the single-agent approach considers a single time-preference rate. Doing otherwise would endow the most altruistic dynasty with the highest saving rate and eventuate in its holding all of the economy's wealth. The single-agent model has another major theoretical drawback. Intermarriage across any two dynasties links the two dynasties altruistically and, given even a very small rate of intermarriage, links the entire planet altruistically. This issue was first pointed out by Kotlikoff (1983) and then studied in detail by Bernheim and Bagwell (1988). However, the most important reason for questioning the single-agent approach is the abundant evidence, at least in the US, rejecting operative intergenerational altruism - evidence that includes Abel and Kotlikoff (1994), Altonji et al. (1992), Hayashi et al. (1996), Gokhale et al. (1996), and Altonji et al. (1997).

Modelling Choice. Kotlikoff et al. (2021) introduced the concept of a UWI carbon tax in an OLG model, albeit with a single region. Developing, as we do here, a regional model raises major modeling, methodological, computational, and calibration challenges. However, doing so makes it possible to consider ten critical climate-change realities.

The first is that some regions benefit from climate change. The second is that given nonlinearities in climate damages, one needs to disaggregate regionally region to accurately calculate the optimal UWI global carbon tax and the generation- and region-specific net transfers needed to implement Pareto improvements. Third, the magnitude and duration of fossil-fuel usage differs according to region. Fifth, changes in the course of GDP due to carbon policy will differ by region, which, in turn, will impact global emissions, which, in turn, will impact region-specific GDP paths. Consequently, disaggregation presents a more multifaceted simultaneity challenge for calculating optimal carbon policy. Sixth, region-specific generations that are slated to suffer the most from climate change will, under UWI policy, need to pay the highest taxes to compensate for their out-sized climate gains. Collecting such taxes raises questions of compliance and whether limiting compensatory taxation by some will come at a major loss of Pareto gains to others. Seventh, certain regions, such as China, may not agree to tax carbon. Consequently, a regional model is needed to understand what welfare gains subsets of regions can achieve on their own. Eighth, disaggregating by regions raises the question of how to maintain carbon cooperation across regions through time. The ninth is the need to develop an algorithm to compute global, intertemporal Pareto policies. And the tenth is to understand how policy delay limits welfare gains in a realistic multi-region setting.

Our model features three goods: i) output, which can be consumed or invested (used as capital), ii) clean energy, and iii) dirty energy. Output is produced with capital, labor, and energy, be it clean or dirty. Clean energy is produced with capital, labor, and land. Each region's land is in fixed supply, which proxies for region-specific physical limits on generating clean energy. This input fixity ensures that clean energy is always produced, including in the early stages of the transition when its technology is limited. As for dirty energy, its production is, as indicated, based on the increasingly costly extraction of fossil fuels. Since our model is deterministic and agents are indifferent between holding particular assets, we treat dirty energy companies as globally owned.

Under BAU, that is, no policy, our assumed technological advances in clean energy bring an end to dirty energy's use at region-specific dates. Regions with limited initial clean-energy use have, per our calibration, low initial clean-energy productivity. Consequently, they take longer to wean themselves off fossil fuels. Thus, under BAU, Sub-Saharan Africa uses dirty energy 
through the end of the next century, whereas the US stops much sooner. Unfortunately, even though clean energy's productivity growth brings an end under BAU to carbon emissions, the regional carbon end dates are sufficiently distant to permit dirty energy to wreak long-lasting, major damages. Moreover, the worst damage arises in regions that house the vast majority of the world's current and future populations.

As indicated, our model's UWI policy has two components. First, it taxes carbon emissions at time-varying rates equal to year $t$ 's social cost of carbon (SCC) - the present value of the future global cost of an extra current ton of emissions produced in $t$ ? $^{2}$ Second, it lump-sum redistributes (compensates) on a generation- and region-specific basis to ensure that all cohorts in all regions experience an identical welfare gain. Given that we are pricing the externality correctly at each point in time, our algorithm delivers the maximum UWI, UWIF, and UWIL carbon-tax policies. As for carbon-tax revenues, they are lump-sum rebated to dirty energy producers on a period-by-period basis $3^{3}$ As pointed out by Goulder (1995), carbon revenues could be used to reduce other distortions, delivering a "double dividend" and, thus, a higher UWI gain than that computed here

Who pays (measured as a share of lifetime consumption) the most in compensatory net taxes? Clearly, it is future generations in regions that gain the most from a cooler planet. However, their tax payments are worth the price, leaving them better off to the same percentage degree as all current and future generations in all other regions. How can the policy's redistribution be implemented in practice? An international authority, such as the International Monetary Fund, could issue green bonds to initially make net transfers and subsequently collect taxes to service the debt.

Our study makes five significant methodological contributions. First, to repeat, it builds, to the best of our knowledge, the first large-scale OLG IAM model with region-specific emissions and damages. Second, our model, like Krusell and Smith (2018) and others, determines regionspecific temperatures (which are required to derive region-specific damages) based on a climatescience technique called "pattern scaling". The latter method can be used to compute the local temperature at grid resolutions as fine as 1-degree latitude by 1-degree longitude, given the global average temperature $5^{5}$ Third, our solution takes account of the feedback loop in which the path of global temperature impacts the paths of region-specific temperature, the paths of region-specific temperatures determine region-specific damages, the paths of region-specific damages help determine the paths of region-specific production, including dirty-energy use and, thus, emissions, and the sum of paths of region-specific emissions determines global emissions and, thus, the global temperature path. Fourth, in determining region-specific damages, we rely on Krusell and Smith (2018)'s damage function (albeit based on our calibration), which admits negative damages while delivering approximately the same aggregate damages as the DICE-2016 (henceforth, simply DICE) model (Nordhaus, 2017).

Finally, we use Folini et al. (2021)'s recent study that employs state-of-the-art climate modeling to re-calibrate Nordhaus' DICE functions governing the relationships between global emissions, carbon concentration, and global mean temperature.

\footnotetext{
${ }^{2}$ Taxing fossil fuel extraction rather than fossil fuel usage would generate identical results.

${ }^{3}$ Rebating carbon revenues to dirty energy suppliers does not alter outcomes. For example, were we to rebate carbon revenues on a global per capita basis, the UWI region- and generation-specific net transfers would adjust to maintain the original equilibrium.

${ }^{4}$ We reserve such analysis for future work.

${ }^{5}$ See, e.g., Lynch et al. (2017), Kravitz et al. (2017), and references therein.
} 
Preview of Findings. In our baseline, high damage scenario, the BAU rise in the planet's mean surface temperature through 2200 is approximately 3.7 degrees Celsius. This is moderately good news for Canada and Russia, whose 2200 GDP levels are 2.6 percent and 3.9 percent higher, respectively. However, the remaining 16 regions suffer, with India, the South Asian Pacific, Sub-Saharan Africa, and the Middle East being hit the worst. Relative to a world with no carbon-based damage, their GDP levels in the year 2200 are reduced by 43.9, 38.3, 37.9, and 36.0 percent, respectively. As for global GDP, it's 2200 value is reduced by 16.7 percent. In the BAU scenario, dirty energy lasts 200 years. In contrast, optimal UWI policy endogenously ends all dirty energy usage in 85 years and dramatically reduces cumulative oil, gas, and coal consumption by 84.4 percent, 86.2 percent, and 98.1 percent, respectively. These major impacts limit the rise in the global mean surface temperature to 2.1 degrees Celsius. Moreover, the peak global GDP loss declines from 16.7 percent to 9.1 percent. Peak regional damages now range from 0.5 percent to 27.8 percent of GDP compared with the range from 2.1 percent to 43.9 under BAU. The striking messages here are both encouraging - global carbon taxation can significantly mitigate losses from climate change - and discouraging - atmospheric carbon concentration is already so high that the optimal UWI carbon tax policy can only limit peak global damages by 44.3 percent.

How large is the optimal UWI? It is 4.3 percent measured as a consumption compensating variation. Thus, implementing UWI is equivalent to increasing the annual consumption of each cohort, whether already born or yet to be born, by 4.3 percent under BAU. Implementing UWI policy requires substantial inter-generational and inter-regional net transfers. The largest transfers, around 15 percent of annual and, thus, lifetime consumption, are made to current and near-term generations in three regions, namely, Russia, Former Soviet Central Asia, and Eastern Europe. These regions experience particularly large increases in energy costs, not due to their ownership or production of fossil fuels (recall, fossil fuels are a global asset), but due to their heavy use of fossil fuels in production.

In contrast, Indian generations born after the year 2200 face the largest taxes - roughly 40 percent of lifetime consumption. This reflects the huge benefit future Indians accrue from carbon taxation. Generations born in the long run in the Middle East, Latin America excluding Mexico and Brazil, Sub Saharan Africa, Brazil, and the South Asian Pacific face net taxes equal to roughly 30 percent of their lifetime consumption. As for those born in the long run in the US, Japan/South Korea/Hong Kong, China, South Africa, Australia, and New Zealand, the net tax is equivalent to almost 15 percent of lifetime consumption.

The time consistency problem raised by the UWI solution is clear. Once the danger of climate change has been reduced, policy beneficiaries may choose not to service outstanding green bonds or refuse to do so beyond a limit. One response is to consider UWIF policy, which limits the UWI gain to future generations, leaving, as mentioned, current generations at their BAU levels of remaining lifetime utility. The 7.7 percent UWIF gain is, as expected, significantly higher than the 4.3 UWI gain. Moreover, UWIF policy does reduce the very high taxes facing many future cohorts. However, it still leaves future generations in otherwise badly hurt regions facing very high net taxes. In India's case, the net tax peaks at 38.2 percent with UWIF policy rather than 39.9 percent with UWI policy.

As an alternative, we consider the aforementioned UWIL policy, where the L refers to limiting any generation's net tax to 10 percent of their lifetime consumption. Under UWIL, all generations in all regions whose tax is not limited experience a 4.0 percent welfare gain. All 
tax-limited, region-specific generations experience a larger welfare gain. For example, India's peak gain is 35.6 percent for the generation born in 2285 .

One of our model's key advantages is the ability to assess carbon taxation enacted by only a subset of regions. We find that no region can materially improve climate change if it operates solely on its own. Coalitions of regions can make a difference for themselves. For example, if all regions apart from China adopt a UWI carbon policy, their uniform welfare gain would be about 60 percent of the value were China also to participate. ${ }^{6}$ This said, the emissions reduction achievable in this century by any coalition that excludes China is far less than half of the reduction were China to be included. In short, China's participation in carbon policy is a sine qua non for real progress against climate change.

Another key finding involves Sinn (2009)'s Green Paradox - the proposition that delay in implementing carbon taxation can, due to dirty-energy producers' adoption of a use it or lose it strategy, dramatically undermines the value of carbon taxation. Indeed, it could render carbon taxation counterproductive. Use it or lose it is of most concern when fossil fuels can be extracted at zero marginal cost. Since our model features costly extraction, delay in policy initiation is less of a concern. Unfortunately, the size of the UWI gain is still reduced by 35 percent - to 2.8 percentage points - if the policy's implementation is delayed for 20 years.

Finally, our model provides insight into a key issue that is largely independent of climate change and climate policy, namely, the future of economic power (i.e., the regional distribution of GDP). Although we relegate the analysis of this tangential issue to the Appendix, our findings are striking. Thanks to catch-up productivity growth coupled with its population size, China will become the world's dominating economy by the century's end, accounting for almost onethird of world GDP compared with roughly 16 percent today. In contrast, the US global-GDP share declines from a quarter now to 16 percent in 2100. In short, China and the US will switch economic places in the coming decades.

The remaining article is organized as follows. In section 2, we proceed with a brief review of the related literature. Section 3 presents our model. Section 4 describes the model's calibration. Section 5 presents our findings. Finally, section 6 concludes.

\section{Literature Review}

There is a vast and growing body of literature on exhaustible resources and climate change emanating from seminal contributions by Hotelling (1931), Solow (1974b a), Nordhaus (1979), and $\operatorname{Sinn}(2009)$. Our paper builds on early, small-scale OLG models of resource extraction and global warming (see, e.g., Howarth and Norgaard (1990), Howarth $(\overline{1991 b})$, Howarth (1991a), Burton (1993), Pecchenino and John (1994), John et al. (1995), Marini and Scaramozzino (1995), and Burton (1993)). Howarth (1991b) is of particular relevance since he considered, in general terms, how to analyze economic efficiency in OLG models in the presence of natural resources. Howarth and Norgaard (1992) introduced damages to the production function from environmental degradation and studied the problem of sustainable development 7 Rasmussen

\footnotetext{
${ }^{6}$ This would entail all regions but China taxing carbon at the global SCC value and the IMF or a similar agency redistributing welfare gains among generations in all regions apart from China to achieve a UWI gain.

${ }^{7}$ An alternative approach to incorporating a negative environmental externality is to include environmental quality directly in the utility function. Pecchenino and John (1994) and John et al. (1995) make this assumption in a discrete-time OLG model. Marini and Scaramozzino (1995) do the same but in a continuous-time OLG
} 
(2003) and Wendner (2001) examine the impact of the Kyoto Protocol on the future course of the energy sector. Wendner (2001) also considers the extent to which carbon taxes can shore up Austria's state pension system. These latter two studies feature large-scale, perfect-foresight, single-country models. However, they omit climate damage.

Howarth and Norgaard (1990), using a pure exchange OLG model, and Howarth (1991a), using a standard OLG model, emphasize that policymakers can choose among an infinite number of Pareto paths in correcting externalities. Clearly, social judgments will matter in deciding which, if any, of such paths to adopt ${ }^{8}$ The continuum of available Pareto improvements holds in our setting as it does in general. However, only the UWI policy path treats everyone equally, at least percentage-wise. Moreover, a carbon-tax cum net transfer policy delivering equal percentage gains to all current and future generations, no matter their region, seems likely to gain universal support. The same is true of UWIL policy since everyone would have a vested interest in ensuring the carbon-tax policy is sustainable.

The fact that OLG models do not admit unique solutions when it comes to allocating efficiency gains across agents, including agents born at different dates, has led some economists to introduce social welfare weights. Papers in this genre include Burton (1993), Calvo and Obstfeld (1988), Endress et al. (2014), Howarth (1998), Ansuategi and Escapa (2002), Marini and Scaramozzino (1995), Schneider et al. (2012), and Lugovoy and Polbin (2016). In these studies, the social planner's time preference plays a critical role in influencing policy choice. However, this approach, like much of the literature, simply confounds normative and positive analysis. Once one has a model that generates individual outcomes for different policies, displaying those outcomes for a range of policy choices appears to be the economist's role - not, in effect, lobbying for the researcher's preferred intergenerational welfare weighting.

Apart from Kotlikoff et al. (2021), our paper's closest antecedents are Bovenberg and Heijdra (1998, 2002), Heijdra et al. (2006), Karp and Rezai (2014). Their studies consider the use of debt policy to achieve Pareto improvements in the context of adverse climate change 9 However, these models differ from ours in two important ways. First, they confine environmental damages to the utility function. Second, they do not model clean and dirty energy, with dirty energy exhausting in the future based on the speed of technological change in the clean energy sector.

Nordhaus' seminal climate change paper (Nordhaus, 1979) - the Dynamic Integrated Model of Climate and the Economy (DICE) - spawned a massive literature, including Nordhaus' development of the RICE (the Regional Integrated model of Climate and the Economy) model (Nordhaus and Yang, 1996, Nordhaus, 2010, 2015), which examines how region-specific production of and damages from global warming underlies the global problem. Hassler et al. (2020) presents a quantitative integrated assessment model (IAM) designed as a dynamic, multi-region general-equilibrium model coupled with climate and carbon-cycle modules. Their IAM setup is aimed toward policy evaluation, focusing on policies that: (i) are not necessarily optimal

framework. The problem of generational equity and sustainable development is also discussed by Mourmouras (1991, 1993), Batina and Krautkraemer (1999) in a model where energy is renewable.

¿Gerlagh and Keyzer (2001), Gerlagh and van der Zwaan (2001) consider the choice among Pareto paths and the potential use of trust-fund policies to provide future generations a share of the income derived from the exploitation of natural resources. Gerlagh and van der Zwaan (2001) also point out that demographics can impact the set of efficient policy paths through their impact on the economy's general equilibrium.

9 Karp and Rezai (2014) also considers a life-cycle model but explores the degree to which policy-induced general equilibrium changes in factor and asset prices could effect a Pareto improvement with no direct redistribution across generations. 
and (ii) potentially differ quantitatively and qualitatively across regions. Their model features a single infinitely lived agent in each region and region-specific production of clean and dirty energy. Unlike RICE, they model resource extraction explicitly.

Hillebrand and Hillebrand (2020) also posit a dynamic climate model with multiple regions to evaluate how implementing an optimal climate tax affects production, emissions, and welfare in each region. Their model distinguishes six major world regions and incorporates a wide array of regional heterogeneities, including a detailed description of the energy production process in each region. As in Hassler et al. (2020), there is a single infinitely lived agent in each region. However, in contrast to Hassler et al. (2020), they assume international capital mobility. Interestingly, their model's optimal tax policy is independent of transfers across regions since, with identical homothetic utility across all agents, neither the interest rate nor emissions are affected by the wealth distribution. This is quite different from our results, where transfers across generations can have large effects on the world interest rate.

The ongoing research by Krusell and Smith Jr (2018) considers a model with 19, 000 regions and studies the distributional effects of climate change and climate policy. As detailed below, we use their calibration strategy to obtain region-specific damages. The main upshot of their work is that since extremely cold regions gain and other regions lose via climate change, a Pareto-improving carbon tax requires transfers to the extremely cold regions. Below, we use the same functional form for specifying regional damages as proposed by Krusell and Smith Jr (2018), but apply our calibration.

Cruz and Rossi-Hansberg (2021) develop a dynamic economic assessment model of the world economy with high spatial resolution. Their model features several endogenous climateadaptation mechanisms absent in our paper. These include costly migration, changes in fertility, alterations in patterns of trade, and impacts on technological change. This aside, our model's structure is very different. In particular, our model includes finite-lived, selfish agents, dirty-energy and capital mobility, and region-specific technologies for producing output. In addition, we focus on Pareto efficiency rather than social welfare. These differences not withstanding, Cruz and Rossi-Hansberg (2021) estimate local climate damages generally in line with our estimates.

A series of papers on the economic geography of climate change (Peri and Robert-Nicoud, 2021) are also of relevance. They discuss how climate change yields heterogeneous effects across space, and they stress that geographic mobility as a key form of climate adaptation (Conte et al., 2021, Castells-Quintana et al., 2020, Indaco et al., 2020, Bosetti et al., 2020, Grimm, 2019), an issue earmarked for our own future research. Finally, there is literature on optimal carbon pricing together with cross-regional transfer schemes designed to maximize participation (see Klis and McGinty (2022)). We discuss a simple institutional setup that can facilitate, but not guarantee, compliance in our setup.

\section{The Model}

We first descibe in section 3.1 our model's region-specific representative firm and then, in section 3.2 , households. In section 3.3 , we define a competitive equilibrium. Section 3.4 describes the climate emulator used in our computations and section 3.5 the computational method to solve the model. For the detailed calibration of the model presented in this section, we refer to section 4 and appendix A.1, whereas appendix A.4 provides additional details on the solution 
procedure.

\subsection{Firms}

Firms in each region, $z$, in each period, $t$, produce final output, $Y_{z, t}$, with capital, $K_{z, y, t}$, labor, $L_{z, y, t}$, and energy, $E_{z, t}$, according to

$$
Y_{z, t}=A_{z, t} K_{z, y, t}^{\alpha_{z}} L_{z, y, t}^{\beta_{z}} E_{z, t}^{1-\alpha_{z}-\beta_{z}},
$$

where the subscript $y$ denotes the use of capital and labor in producing final output, and $\alpha_{z}$ and $\beta_{z}$ are region-specific final-output capital and labor shares. $A_{z, t}$ references region-specific total factor productivity (TFP).

Profit maximization implies

$$
\begin{gathered}
\alpha_{z} A_{z, t} K_{z, y, t}^{\alpha_{z}-1} L_{z, y, t}^{\beta_{z}} E_{z, t}^{1-\alpha_{z}-\beta_{z}}=r_{t}+\delta, \\
\beta_{z} A_{z, t} K_{z, y, t}^{\alpha_{z}} L_{z, y, t}^{\beta_{z}-1} E_{z, t}^{1-\alpha_{z}-\beta_{z}}=w_{z, t},
\end{gathered}
$$

and

$$
\left(1-\alpha_{z}-\beta_{z}\right) A_{z, t} K_{z, y, t}^{\alpha_{z}} L_{z, y, t}^{\beta_{z}} E_{z, t}^{-\alpha_{z}-\beta_{z}}=p_{z, t},
$$

where $r_{t}$ is the world interest rate, reflecting our assumption of perfect capital mobility. The term $\delta$ denotes the capital's depreciation rate, assumed identical across regions. The terms $w_{z, t}$ and $p_{z, t}$ reference, respectively, region-specific wages and prices of energy at time $t$.

Clean-energy production, $S_{z, t}$, obeys

$$
S_{z, t}=B_{z, t} K_{z, s, t}^{\theta} L_{z, s, t}^{\varphi} H_{z, t}^{1-\theta-\varphi},
$$

where $B_{z, t}, K_{z, s, t}, L_{z, s, t}, H_{z, t}$ reference, respectively, the clean energy sector's region- and timespecific productivity level and its demands for capital, labor, and land, where $s$ references clean energy. The parameters $\theta$ and $\varphi$ are clean-energy production parameters.

Profit maximization in producing clean energy requires

$$
\begin{gathered}
p_{z, t}^{S} \theta B_{z, t} K_{z, s, t}^{\theta-1} L_{z, s, t}^{\varphi} H_{z, t}^{1-\theta-\varphi}=r_{t}+\delta, \\
p_{z, t}^{S} \varphi B_{z, t} K_{z, s, t}^{\theta} L_{z, s, t}^{\varphi-1} H_{z, t}^{1-\theta-\varphi}=w_{z, t},
\end{gathered}
$$

and

$$
p_{z, t}^{S}(1-\theta-\varphi) B_{z, t} K_{z, s, t}^{\theta} L_{z, s, t}^{\varphi} H_{z, t}^{-\theta-\varphi}=n_{z, t},
$$

where $n_{z, t}$ is the region- $z$, time- $t$ rental price of land and $p_{z, t}^{S}$ is region $z$ 's price of clean energy.

Total regional energy consumption satisfies

$$
E_{z, t}=S_{z, t}+E_{z, t}^{D}
$$

where $E_{z, t}^{D}$ is a dirty energy composite produced via a CES production function, namely

$$
E_{z, t}^{D}=\left(\kappa_{z, o}^{\frac{1}{u}} O_{z, t}^{\frac{u-1}{u}}+\kappa_{z, g}^{\frac{1}{u}} G_{z, t}^{\frac{u-1}{u}}+\kappa_{z, \mathcal{C}}^{\frac{1}{u}} \mathcal{C}_{z, t}^{\frac{u-1}{u}}\right)^{\frac{u}{u-1}}
$$


where $O_{z, t}, G_{z, t}$, and $\mathcal{C}_{z, t}$ reference oil, gas, and coal consumption, respectively, measured in British thermal units (Btu). The terms $\kappa_{O}, \kappa_{G}$, and $\kappa_{\mathcal{C}}$ are CES share coefficients. The parameter $u$ represents the elasticity of substitution between different dirty energy sources 10

Oil, gas, and coal trade freely on the world market at prices $p_{t}^{O}, p_{t}^{G}$ and $p_{t}^{\mathcal{C}}$. Clean energy is non-tradeable. Cost minimization in producing a unit of dirty energy implies the following demands for alternative dirty energies:

$$
\begin{aligned}
& O_{z, t}=\kappa_{z, O} E_{z, t}^{D}\left(\frac{p_{t}^{O}}{p_{z, t}^{D}}\right)^{-u}, \\
& G_{z, t}=\kappa_{z, G} E_{z, t}^{D}\left(\frac{p_{t}^{G}}{p_{z, t}^{D}}\right)^{-u}, \\
& \mathcal{C}_{z, t}=\kappa_{R, \mathcal{C}} E_{z, t}^{D}\left(\frac{p_{t}^{\mathcal{C}}}{p_{z, t}^{D}}\right)^{-u},
\end{aligned}
$$

where the price of the dirty energy composite is given by

$$
p_{z, t}^{D}=\left(\kappa_{z, O}\left(p_{t}^{O}\right)^{1-u}+\kappa_{z, G}\left(p_{t}^{G}\right)^{1-u}+\kappa_{z, \mathcal{C}}\left(p_{t}^{\mathcal{C}}\right)^{1-u}\right)^{\frac{1}{1-u}}
$$

Decreasing returns to scale in the clean-energy production sector ensures nonzero production of clean energy in each region regardless of the price of energy. Thus, $S_{z, t}>0$ holds in equilibrium as well as $p_{z, t}=p_{z, t}^{S}$. On the other hand, the price of the dirty energy composite, $p_{z, t}^{D}$, can exceed the price at which energy demand is fully met by clean energy. When this occurs in a given region, there is no demand for the dirty energy composite, and the use of fossil fuels ends. The following equations encompass this outcome. They reflect cost minimization and the constraint that dirty-energy consumption is non-negative.

$$
\begin{gathered}
p_{z, t}=p_{z, t}^{D}-\chi_{z, t}, \\
\chi_{z, t} E_{z, t}^{D}=0, \\
E_{z, t}^{D} \geq 0,
\end{gathered}
$$

and

$$
\chi_{z, t} \geq 0
$$

Note that when dirty energy production is zero, its Lagrange multiplier, $\chi_{z, t}$, is positive, indicating, from equation (15), that producing a unit of dirty energy costs more than producing a unit of clean energy.

Dirty energy producers, indexed by their energy-type, $M \in\{O, G, \mathcal{C}\}$, have finite energy reserves, $R_{t}^{M}$. The costs of extracting these reserves are increasing in the cumulative amounts

\footnotetext{
${ }^{10}$ One can question, per Hassler et al. (2012), at least the short-run realism of perfect clean and dirty energy substitutability. Boeing 747 jets, for instance, cannot yet fly on batteries although lighter planes can (see, e.g., https://aroundtheworld.solarimpulse.com). However, assuming less than perfectly clean and dirty energy substitutability would mean the indefinite use of fossil fuels, which we view as unrealistic. It would also preclude long-run balanced growth, which would preclude our solution method.
} 
extracted. We posit the following functional form for the extraction cost of dirty energy of type $M$ per unit of dirty energy extracted:

$$
c_{t}^{M}\left(R_{t}^{M}\right)=\left(\xi_{1}^{M}+\xi_{2}^{M}\left(R_{0}^{M}-R_{t}^{M}\right)+\left(\frac{1}{R_{t}^{M}}\right)\right) .
$$

Note that the last term in equation 19 ensures that all three extraction costs approach infinity as reserves approach zero.

Dirty energy firms maximize market value, $V_{t}^{M}$, given by

$$
V_{t}^{M}=\sum_{j=0}^{\infty}\left[\left(p_{t+j}^{M}-c_{t+j}^{M}\left(R_{t+j}^{M}\right)-\varrho^{M} \tau_{t+j}\right) M_{t+j}+\mathcal{T}_{t}^{M}\right]\left(\prod_{i=0}^{j} \frac{1}{1+r_{t+i}}\right),
$$

subject to

$$
\begin{gathered}
R_{t}^{M}=R_{t-1}^{M}-M_{t}, \\
-R_{t}^{M} \leq 0
\end{gathered}
$$

and

$$
-M_{t} \leq 0
$$

where $p_{t}^{M}$ is the global price of a unit of dirty energy, $M_{t}$, at $t, \varrho^{M}$ is the amount of CO2 emitted per unit of energy of type $M$ (measured in Btu), $\tau_{t}$ is the absolute tax per unit of CO2 emitted at $t$, and $\mathcal{T}_{t}^{M}$ is the lump-sum rebate of time- $t$ carbon taxes to type $M$ dirty energy producers.

The dirty-energy Kuhn-Tucker conditions are given by

$$
p_{t}^{M}-c_{t}^{M}\left(R_{t}^{M}\right)-\varrho^{M} \tau_{t}-\ell_{t}^{M}+\mu_{t}^{M}=0,
$$

and

$$
\frac{\partial c_{t}^{M}\left(R_{t}^{M}\right)}{\partial R_{t}^{M}} M_{t}+\ell_{t}^{M}-\frac{\ell_{t+1}^{M}}{1+r_{t+1}}-\psi_{t}^{M}=0
$$

where $\ell_{t}, \psi_{t}$ and $\mu_{t}$ are non-negative Lagrange multipliers for the restrictions in equations (21), (22), and (23), respectively.

The complementary slackness conditions are given by:

$$
M_{t} \mu_{t}^{M}=0
$$

and

$$
R_{t}^{M} \psi_{t}^{M}=0
$$

The value of land, $Q_{z, t}$, equals the present value of future land rents, that is:

$$
Q_{z, t}=\sum_{j=0}^{\infty} n_{z, t+j} H_{z, t+j}\left(\prod_{i=0}^{j} \frac{1}{1+r_{t+i}}\right) .
$$




\subsection{Households}

Agents enter the workforce at age 20 and face an annual idiosyncratic mortality risk through age 100, that is, their maximum age of life. Age-specific mortality risk, which is region- and year-specific, is fully hedged via an actuarially fair annuities market ${ }^{11}$ Region- and year-specific mortality probabilities by age are calibrated based on UN demographic projections (see United Nations (2019a) and United Nations (2019b)).

Agents born in region $z$ in year $t$ maximize

$$
U_{z, t}=\sum_{j=1}^{80} P_{z, t+j-1, j} \frac{1}{(1+\rho)^{j}} \frac{C_{z, t+j-1, j}^{1-\sigma}-1}{1-\sigma}
$$

subject to

$$
a_{z, t+1, j+1}=\left(1+r_{t}\right) a_{z, t, j}+w_{z, t} l_{z, t, j} P_{z, t, j}+\mathbb{T}_{z, t, j}-P_{z, t, j} C_{z, t, j},
$$

where $C_{z, t, j}, l_{z, t, j}, P_{z, t, j}$, and $a_{z, t, j}$ reference, respectively, consumption, labor supply, population size, and assets of age- $j$ agents born in region $z$ at time $t$. The term $\mathbb{T}_{z, t, j}$ references net transfers received at age $j$ by the generation born at $t$ in region $z$. Finally, $\rho$ is the time preference rate and $\sigma$ is the coefficient of relative risk aversion.

\subsection{Equilibrium and Debt-Policy}

Total household assets comprise physical capital, the value of dirty energy firms, the value of land, and carbon-policy debt, that is,

$$
\sum_{z=1}^{18} \sum_{j=1}^{80} a_{z, t, j}=K_{t}+V_{t}^{O}+V_{t}^{G}+V_{t}^{\mathcal{C}}+\sum_{z=1}^{18} Q_{t, j}+\mathcal{D}_{t}
$$

where $\mathcal{D}_{t}$ is debt issued to finance carbon policy and where

$$
K_{t}=\sum_{z=1}^{18} K_{z, y, t}+\sum_{z=1}^{18} K_{z, s, t}
$$

Debt evolves according to

$$
\mathcal{D}_{t+1}=\left(1+r_{t}\right) \mathcal{D}_{t}+\sum_{z=1}^{18} \sum_{j=1}^{80} \mathbb{T}_{z, t, j}
$$

The world supplies of oil, gas and coal equal the sum of regional demands

$$
O_{t}=\sum_{z=1}^{18} O_{z, t}, G_{t}=\sum_{z=1}^{18} G_{z, t}, \mathcal{C}_{t}=\sum_{z=1}^{18} \mathcal{C}_{z, t}
$$

Finally, regional supplies of labor equal the sum of their sectoral demands.

$$
L_{z, t} \equiv \sum_{j=1}^{80} P_{z, t, j} l_{z, t, j}=L_{z, y, t}+L_{z, s, t} .
$$

\footnotetext{
${ }^{11}$ This precludes needing to model bequests and inheritances.
} 
IMF refers to the model's redistributive institution $\sqrt{12}$ The IMF needs to assess a net tax of $\mathbb{T}_{z, j, t}$ on generation $j$ in region $z$ in each year $t$. Budget balance implies that

$$
\sum_{t=0}^{\infty}\left(\prod_{\tau=0}^{t} \frac{1}{1+r_{\tau}}\right) \sum_{z=1}^{18} \sum_{j=1}^{80} \mathbb{T}_{z, t, j}=0
$$

or in other words, where debt policy satisfies

$$
\lim _{t \rightarrow \infty} \mathcal{D}_{t+1}\left(\prod_{\tau=0}^{t} \frac{1}{1+r_{\tau}}\right)=0 .
$$

\subsection{Modeling the Climate}

To describe the evolution of the climate in our multi-region OLG model, we adopt the functional form of DICE (Nordhaus, 2017), which relates output to emissions, emissions to carbon concentration, and carbon concentration to global temperature, but use a parameterization proposed by Folini et al. (2021) and which is based on the latest findings from climate science

DICE mimics the carbon cycle via three carbon reservoirs: the atmosphere (A), the upper ocean (U), and the lower ocean (L). The process by which output increases atmospheric carbon concentration is given by

$$
\left(\begin{array}{c}
J_{t}^{A} \\
J_{t}^{U} \\
J_{t}^{L}
\end{array}\right)=\Phi^{J}\left(\begin{array}{l}
J_{t-1}^{A} \\
J_{t-1}^{U} \\
J_{t-1}^{L}
\end{array}\right)+\left(\begin{array}{c}
\varrho^{O} O_{t}+\varrho^{G} G_{t}+\varrho^{\mathcal{C}} \mathcal{C}_{t}+E_{t}^{\text {Land }} \\
0 \\
0
\end{array}\right)
$$

where $J_{t}^{A}, J_{t}^{U}, J_{t}^{L}$ are the $\mathrm{CO}_{2}$ concentrations in the atmosphere, the upper ocean, and the lower ocean. $\Phi^{J}$ is a 3 by 3 matrix of parameters governing the mass transfer across the three reservoirs with units "mass fraction per time step". $E_{t}^{\text {Land }}$ is land-based carbon emission, which obeys the following relationship.

$$
E_{t}^{\text {Land }}=E_{0}^{\text {Land }} e^{-\delta^{\text {Land }} t}
$$

where $\delta^{\text {Land }}$ is the rate at which land-based emissions decline. $\mathrm{CO}_{2}$ in the atmosphere impacts radiative forcing, $F_{t}$, according to

$$
F_{t}=\eta_{1} \frac{\log \frac{J_{t}^{A}}{J^{0}}}{\log (2)}+F_{t}^{E X}
$$

where $J^{0}$ is the pre-industrial concentration of atmospheric carbon. $F_{t}^{E X}$ references time- $t$ radiative forcing, which is assumed to evolve as

$$
F_{t}^{E X}=F_{0}^{E X}+\frac{1}{T^{\prime}}\left(F_{1}^{E X}-F_{0}^{E X}\right) \min \left(t, T^{\prime}\right)
$$

where $F_{0}^{E X}$ and $F_{1}^{E X}$ are the exogenous values of radiative forcing in the initial period, 2017 and 2100, respectively. $T^{\prime}$ references years between 2017 and 2100.

\footnotetext{
${ }^{12}$ This is the Lump Sum Redistribution Authority (LSRA) of Auerbach and Kotlikoff (1987).

${ }^{13}$ The parameters governing carbon concentration are provided in section 4
} 
In DICE, the temperature evolves according to a two-layer energy balance model, that is,

$$
\left(\begin{array}{c}
T_{t}^{A} \\
T_{t}^{L}
\end{array}\right)=\Phi^{T}\left(\begin{array}{l}
T_{t-1}^{A} \\
T_{t-1}^{L}
\end{array}\right)+\left(\begin{array}{c}
\eta_{2} F_{t} \\
0
\end{array}\right)
$$

which formally corresponds to the evolution described in Geoffroy et al. (2013). In equation (41), $T_{t}^{A}$ and $T_{t}^{L}$ denote the global mean temperature change, relative to pre-industrial levels, of the upper layer (atmosphere and upper ocean) as well as the lower layer (deep ocean), respectively, at the time step $t$. From a physics perspective, the free parameters in equation (41), including the matrix $\Phi^{T}$, may be interpreted as a heat exchange coefficient between the upper and lower layers, the effective heat capacities of the upper and lower layer, and the ratio of forcing arising from a doubling of $\mathrm{CO} 2$ to the associated temperature change.

Our IAM requires knowledge of regional climate damages and, thus, regional temperatures. We infer regional from global temperature using a popular technique from climate sciences called "pattern scaling" (see, e.g., Tebaldi and Arblaster (2014), Lynch et al. (2017), Kravitz et al. (2017), and references therein). Pattern scaling, first introduced by Santer et al. (1990), is a statistical method that, based on large-scale Earth system models, relates, for instance, the global average temperature, $T_{t}^{A}$, in a computationally efficient fashion to local temperatures at resolutions as fine as about $1^{\circ}$ longitude $\times 1^{\circ}$ latitude.

Our computations use the publicly available pattern-scaling repository by Lynch et al. (2017).14 Specifically, we use the CCSM4 model that follows the RCP8.5 for all our computations. This choice minimizes our model's interpolation error in ascribing temperature to the $1^{\circ}$ longitude $\times 1^{\circ}$ latitude grids we use to map global to local temperature. Our results are robust to the choice of RCP scenarios in connecting global average temperature to grid-specific and, thus, region-specific temperature (Link et al., 2019).

In computing the regional average surface temperatures, $T_{z, t}$, we apply pattern scaling as follows. First, we compute $T_{t}^{A}$ (cf. equation (41)). Second, we derive local temperatures on a $1^{\circ}$ by $1^{\circ}$ grid, each of which belongs to a certain region of our model. Third, we use cell-specific GDP values to weigh cell-specific temperature values to produce our regional GDP-weighted average temperatures ${ }^{15}$

The "handshake" of the climate emulator and the economics block of the model is done at the level of temperature-dependent damages to TFP. We model regional TFP, $A_{z, t}$, as the product

\footnotetext{
${ }^{14}$ The respective data sets and codes can be found at URL: https://github.com/JGCRI/CMIP5_patterns Each function relating local average to global average temperature is determined by using calculations from dozens of large-scale climate models developed by climate scientists across the world. Their calculations are organized by CMIP5 (Taylor et al., 2012) - the Coupled Model Intercomparison Project Phase 5, which collects climate-model calculations for specific greenhouse gas scenarios called representative concentration pathways (RCP). The four primary RCP scenarios are denoted as RCP2.6, RCP4.5, RCP6, and RCP8.5. Each RCP scenario generates particular paths of greenhouse gases, aerosols, and other climatically relevant forcing agents over the 21st century. The RCP8.5 scenario, for instance, reflects a "BAU " narrative, in which total anthropogenic forcing reaches approximately $8.5 \mathrm{~W} / \mathrm{m}^{2}$ in the year 2100. Conversely, the RCP2.6 scenario involves aggressive decarbonization, causing radiative forcing to peak at approximately $3 \mathrm{~W} / \mathrm{m}^{2}$ around 2050 and to decline to approximately $2.6 \mathrm{~W} / \mathrm{m}^{2}$ at the end of the 21st century. For the exact specifications of the RCP scenarios and related data, see Meinshausen et al. (2011), and http://www.pik-potsdam.de/ mmalte/rcps/.

${ }^{15}$ Note that we leverage Nordhaus' G-Econ database to construct the GDP-weighted regional temperature patterns (see https://gecon.yale.edu, GEcon 4.0 for 2005). This weighting ensures that the location of human activity dominates the average temperature within a region. In Canada, for example, the GDP-weighted average temperature is concentrated in regions close to the US, whereas the naive average would be driven by cells closer to the North pole.
} 
of a region-specific exogenous trend, $\tilde{A}_{z, t}$, and a regional function, $Z_{z, t}$, which incorporates productivity differences due to differences in temperature. $\tilde{A}_{z, t}$ grows at a time-varying, regionspecific growth rate $g_{z, t}$, that is,

$$
\frac{\tilde{A}_{z, t}}{\tilde{A}_{z, t-1}}=1+g_{z, t} .
$$

Following Krusell and Smith Jr (2018), we assume that the component $Z_{z, t}$ obeys

$$
Z_{z, t}=\left\{\begin{array}{l}
0.02+0.98 e^{\left(-v^{+}\left(T_{z, t}-T^{*}\right)^{2}\right)} \text { if } T_{z, t}>T^{*} \\
0.02+0.98 e^{\left(-v^{-}\left(T_{z, t}-T^{*}\right)^{2}\right)} \text { if } T_{z, t} \leq T^{*}
\end{array}\right.
$$

Regional climate damages are given by

$$
D_{z, t}=1-Z_{z, t} / Z_{z, 1900}
$$

Equation 43) models regional climate-specific TFP as peaking at $T^{*}$ (cf. Krusell and Smith Jr (2018)). Thus, cold regions with temperatures below $T^{*}$ will benefit from global warming as their temperature approaches $T^{*}$. Similarly, hot regions will be harmed as their temperature moves farther away from $T^{*}$. Larger values of $v^{+}$and $v^{-}$raise the cost of a given deviation from the optimal temperature. In our calibration below (cf. section 4 and figure 12 in the Appendix), we choose $v^{+}$to relate regional damage functions to the global damage functions used in the literature 16

\subsubsection{The Social Cost of Carbon}

We define the SCC at $t$ to be the present discounted value of all future damages resulting from an additional unit of $\mathrm{CO} 2$ emitted at $t$. In much of the existing literature (see, e.g., Nordhaus (1979) or Golosov et al. (2014)), this cost is equal to a marginal rate of substitution of a social planner's value function. As explained in the introduction, our model features no social planner. Consequently, we need to determine the SCC by solving for the evolution of temperature and damages for two different emissions paths. We define the SCC at some time $\tau$ as the sum of all damages at times $\tau, \tau+1, \ldots, \infty$ that arise when one extra unit of CO2 is added exogenously to emissions given by equation (37), discounted at the path of the equilibrium world interest rate, minus the discounted sum of all damages that arise without this extra unit. Pareto efficiency requires setting the carbon tax each period to that period's SCC.

\subsection{Computational Method}

Our solution method uses a variant of the Gauss-Seidel iteration technique developed in Auerbach and Kotlikoff (1987). Specifically, it begins with guesses of the level of the UWI welfare gain and the time paths of the aggregate capital stock, oil, coal, gas reserves, global emissions, region-specific total factor productivities, and the carbon tax. It then uses a recursion to solve the model backward from its steady-state, which the economy is assumed to reach in 3017. A

\footnotetext{
${ }^{16}$ The notion that some regions might gain from climate change is controversial given the potential for tipping points causing catastrophic global climate events. However, our certainty-equivalent approach requires incorporating climate-change gains as well as losses.
} 
millennium is clearly a very long time for the economy to stabilize. But it provides the climate's atmospheric carbon concentration sufficient time to stabilize. The recursion determines, on a year-by-year basis, all region-specific and global prices, including the world interest rate, and all region-specific quantities, including all inputs, outputs, and consumption amounts of all cohorts. It also calculates the region- and cohort-specific lump-sum net transfers needed to achieve the guessed UWI gain. These recursively calculated values are used to update the time paths of our guessed global aggregates, regional temperatures, regional damages, regional productivities, and the carbon tax. In addition, we raise (lower) the targeted UWI gain if the present value of net transfers across all regions and generations is negative (positive). Our algorithm is highly precise. Its annual variables converge, relative to their prior guessed values, to less than one-hundredth of one percent. Supplementary details on the algorithm are provided in appendix A.4.

\section{Calibration}

This section summarizes the key components of our calibration strategy. Appendix A.1 provides details. Our 18-region OLG model builds on the 17-region Global Gaidar Model (GGM; cf. Benzell et al. (2017)), but is substantially extended by coupling it to a climate emulator (cf. section 3.4) and by adding an extra region. ${ }^{17}$ Table 1 lists the model's 18 regions and their acronyms, and figure 1 displays them on a map of the globe. The World Bank's Development

Table 1: Regions and their Acronyms.

\begin{tabular}{l|l} 
Acronym & \multicolumn{1}{|c}{$\begin{array}{c}\text { Region } \\
\text { (Excludes Countries Modeled Independently) }\end{array}$} \\
\hline ANZ & Australia and New Zealand \\
BRA & Brazil \\
CND & Canada \\
CHI & China \\
EEU & Eastern Europe \\
GBR & The U.K. \\
IND & India \\
JSHK & Japan, South Korea, and Hong Kong \\
MENA & Middle East and North Africa \\
MEX & Mexico \\
RUS & Russian Federation \\
SAF & South Africa \\
SAP & The South Asian Pacific \\
SLA & Latin America excluding Mexico and Brazil \\
SOV & Former Soviet Central Asia \\
SSA & Sub-Saharan Africa \\
US & USA \\
WEU & Western Europe
\end{tabular}

\footnotetext{
${ }^{17}$ In particular, the GGM's single region consisting of Canada, Australia and New Zealand is split into Canada by itself and ANZ - Australia plus New Zealand.
} 


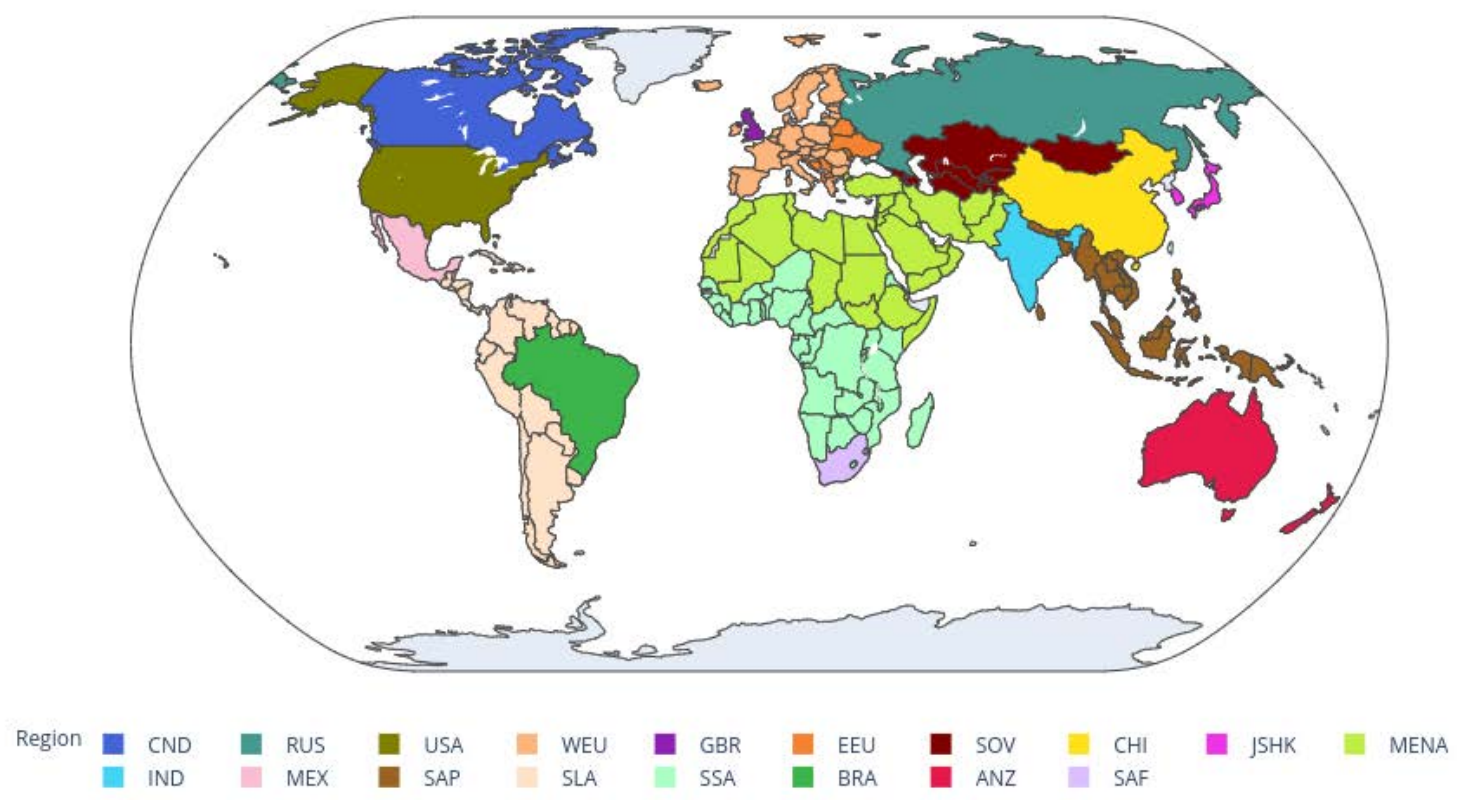

Figure 1: Our global model's 18 regions.

Indicators (WDI) is a main data source, providing, in particular, 2017 GDP values. These are used to calibrate the 2017 levels of regional TFP. Energy consumption/usage data come from the US Energy Information Administration (EIA). These data, measured in Btus, comprise four categories: i) coal, ii) natural gas, iii) petroleum and other liquids, iv) nuclear, renewables, and others. We aggregate energy sources into four composites: coal, gas, oil, and clean energy. Table 2 presents region-specific GDP and energy-consumption data.

The EIA data let us calibrate the region-specific CES production functions specified in equation (10). As in Hillebrand and Hillebrand (2020), we assume an elasticity of substitution between oil, coal, and gas of $u=2$. This value lies between Acemoglu et al. (2012)'s (higher) and Golosov et al. (2014)'s (lower) assumed values. We measure the share parameters, $\kappa_{O}, \kappa_{G}$, and $\kappa_{\mathcal{C}}$, using data on 2017 world energy prices. Taking the $2017 \$ 50.8$ price per barrel of West Texas Intermediate crude and assuming that one barrel of oil contains $5.7 \cdot 10^{6}$ Btus, our 2018 price of oil equals $8.9 \cdot 10^{-6}$ per Btu. Analogous calculations produce a 2017 price of gas of $5.7 \cdot 10^{-6}$ per Btu and a price of coal of $4.5 \cdot 10^{-6}$ per Btu. Normalizing the sum of $\kappa_{O}, \kappa_{G}$, and $\kappa_{\mathcal{C}}$ to 1 , and using equations (11)-(13) provides our region-specific, dirty-energy share parameters. These coefficients are then used to construct the price of the dirty-energy composite per equation (14). This also pins down the 2017 price of clean energy as well as 2017 dirty-energy consumption by region.

The ratio of each region's total energy consumption as a share of its GDP provides our measure of $1-\alpha_{z}-\beta_{z}$. To determine values for $\alpha_{z}$ and $\beta_{z}$, we assume that one-third of this remaining output share is paid to capital with the rest paid to labor.

Table 3 reports region-specific contributions of energy to output as well as contributions of particular energy sources. The table shows remarkable differences across regions in energy reliance - from 2.25 percent of GDP in Great Britain to 14.67 percent in SOV (former Soviet 
Table 2: 2017 GDP (in trillions of 2017 USD), and Energy Consumption (in quad Btus).

\begin{tabular}{c|ccccc} 
& & & & $\begin{array}{c}\text { Petroleum and } \\
\text { Other Liquids }(O)\end{array}$ & $\begin{array}{c}\text { Nuclear, Renewables, } \\
\text { and Other }(S)\end{array}$ \\
\hline ANZ & 1.53 & 1.77 & 1.82 & 2.74 & 0.67 \\
BRA & 2.06 & 0.67 & 1.28 & 6.05 & 4.58 \\
CND & 1.65 & 0.69 & 4.61 & 4.91 & 4.85 \\
CHI & 12.14 & 88.42 & 8.81 & 24.91 & 17.30 \\
EEU & 0.26 & 1.57 & 1.92 & 1.06 & 1.21 \\
GBR & 2.67 & 0.38 & 2.97 & 3.26 & 1.61 \\
IND & 2.65 & 16.62 & 2.09 & 8.96 & 2.81 \\
JSHK & 7.07 & 8.65 & 7.27 & 17.32 & 3.66 \\
MENA & 4.22 & 2.27 & 26.08 & 24.45 & 0.60 \\
MEX & 1.16 & 0.48 & 2.86 & 3.97 & 3.67 \\
RUS & 1.58 & 4.93 & 16.94 & 7.29 & 0.24 \\
SAF & 0.35 & 3.98 & 0.19 & 1.27 & 1.27 \\
SAP & 2.50 & 4.23 & 5.92 & 8.92 & 3.29 \\
SLA & 2.09 & 0.63 & 4.55 & 6.96 & 0.59 \\
SOV & 0.36 & 2.67 & 4.13 & 1.47 & 0.83 \\
SSA & 1.00 & 0.17 & 1.13 & 2.70 & 18.28 \\
US & 19.49 & 13.84 & 28.06 & 37.57 & 17.19 \\
WEU & 15.94 & 9.14 & 14.64 & 25.48 &
\end{tabular}

Table 3: Energy Consumption as a Share of GDP.

\begin{tabular}{c|ccccc} 
& \multicolumn{3}{c}{$\begin{array}{c}\text { Petroleum and } \\
\text { Other Liquids }(O)\end{array}$} & $\begin{array}{c}\text { Nuclear, Renewables, } \\
\text { and Other }(S)\end{array}$ & Total \\
\hline ANZ & $0.52 \%$ & $0.68 \%$ & $1.59 \%$ & $0.32 \%$ & $3.12 \%$ \\
BRA & $0.15 \%$ & $0.36 \%$ & $2.61 \%$ & $1.85 \%$ & $4.97 \%$ \\
CND & $0.19 \%$ & $1.61 \%$ & $2.65 \%$ & $2.23 \%$ & $6.68 \%$ \\
CHI & $3.28 \%$ & $0.42 \%$ & $1.83 \%$ & $0.86 \%$ & $6.39 \%$ \\
EEU & $2.76 \%$ & $4.31 \%$ & $3.67 \%$ & $3.08 \%$ & $13.81 \%$ \\
GBR & $0.06 \%$ & $0.64 \%$ & $1.09 \%$ & $0.46 \%$ & $2.25 \%$ \\
IND & $2.83 \%$ & $0.45 \%$ & $3.01 \%$ & $0.71 \%$ & $6.99 \%$ \\
JSHK & $0.55 \%$ & $0.59 \%$ & $2.18 \%$ & $0.39 \%$ & $3.72 \%$ \\
MENA & $0.24 \%$ & $3.55 \%$ & $5.16 \%$ & $0.35 \%$ & $9.31 \%$ \\
MEX & $0.19 \%$ & $1.42 \%$ & $3.05 \%$ & $0.40 \%$ & $5.06 \%$ \\
RUS & $1.41 \%$ & $6.16 \%$ & $4.11 \%$ & $1.56 \%$ & $13.24 \%$ \\
SAF & $5.13 \%$ & $0.31 \%$ & $3.23 \%$ & $0.43 \%$ & $9.10 \%$ \\
SAP & $0.76 \%$ & $1.36 \%$ & $3.17 \%$ & $0.39 \%$ & $5.67 \%$ \\
SLA & $0.14 \%$ & $1.25 \%$ & $2.96 \%$ & $1.23 \%$ & $5.58 \%$ \\
SOV & $3.36 \%$ & $6.61 \%$ & $3.66 \%$ & $1.04 \%$ & $14.67 \%$ \\
SSA & $0.08 \%$ & $0.65 \%$ & $2.41 \%$ & $0.68 \%$ & $3.81 \%$ \\
US & $0.32 \%$ & $0.83 \%$ & $1.72 \%$ & $0.70 \%$ & $3.57 \%$ \\
WEU & $0.26 \%$ & $0.53 \%$ & $1.42 \%$ & $0.82 \%$ & $3.03 \%$
\end{tabular}

states in Asia). Table 2 also reports our calculated 2017 region-specific GDP and dirty-energy usage levels. The major consumers of fossil fuels are China, at 122.14 quad Btus, the US at 80.01 quad Btus, and Western Europe at 49.26. Even though China's 2017 GDP is less than two-thirds that of the US and only three-fourths that of the WEU, its carbon emissions are twice 
Table 4: Convergence of Non-US Regions' Productivity Relative to US Productivity.

\begin{tabular}{|l|l|l|l|l|l|l|l|l|}
\hline ANZ & BRA & CND & CHI & EEU & GBR & IND & JSHK & MENA \\
\hline$-0.11 \%$ & $0.27 \%$ & $-0.08 \%$ & $2.54 \%$ & $0.09 \%$ & $0.04 \%$ & $1.99 \%$ & $1.92 \%$ & $0.05 \%$ \\
\hline MEX & RUS & SAF & SAP & SLA & SOV & SSA & WEU & \\
\hline$-0.64 \%$ & $-0.06 \%$ & $-0.20 \%$ & $1.09 \%$ & $-0.67 \%$ & $0.87 \%$ & $-0.73 \%$ & $0.76 \%$ & \\
\hline
\end{tabular}

that of the US and three times that of the WEU. This reflects its overwhelming dependence on coal, which arises from its very high value of $\kappa_{\mathcal{C}}$. Indeed, the Chinese value of $\kappa_{\mathcal{C}}$ is almost seven times that of the US. However, the US is hardly a model green citizen. US GDP is one-fifth larger than that of WEU. However, its emissions are three-fifths larger. For further comparisons, table 7 in the Appendix shows region-specific GDP, energy consumption, and CO2 emissions relative to the USA.

We adopt $\theta=0.13$ and $\varphi=0.27$, the clean-energy production parameters specified in equation (5), from Kotlikoff et al. (2021). In particular, we assume that 60 percent of clean energy output is paid to land, with the rest distributed between labor and capital in the same proportion as in the final goods sector. In calibrating TFP levels in the final goods and clean energy production sectors, we assume a 10 percent annual capital depreciation rate and a 4 percent base-year global real interest rate. This implies a 14 percent rental rate on capital. With this rental price, data on regional labor endowments, calculated values of output, and the levels of clean and dirty energy consumption, we compute regional capital demands and TFP values in both sectors using equations (1)-(7). This delivers the year 2017 value of world capital equal to $\$ 178$ trillion 18

To calibrate region-specific productivity growth in final goods production, we rely on univariate, country-specific regressions graciously provided by Müller et al. (2019). We aggregated the country estimates to generate regional productivity growth rates. Table 4 presents these productivity rates relative to the US productivity growth rate. The depicted productivity growth rate differentials are applied through 2100. After 2100, we assume that productivity growth in all regions equals the assumed fixed 1.56 percent US growth rate. As for productivity growth in clean energy, we set it to generate a 0.5 percent per year decline in the steady-state energy price.

We use United Nations population projections (United Nations, 2019b) to calibrate population dynamics. These data account for fertility, mortality, and migration. Figure 11 in the Appendix provides a graphical summary of these data. As indicated, there are pronounced demographic waves in some regions, particularly in Russia. The initial distribution of assets between generations and regions is taken from Benzell et al. (2017). The time preference rate, $\rho$, is calibrated at 1.45 percent per year. The coefficient of relative risk aversion, $\sigma$, is set to 1.45 .

Based on McGlade and Ekins (2015), we calibrate the globally available oil reserves to 600 $\mathrm{GtC}$, global available gas reserves to $400 \mathrm{GtC}$, and global available coal reserves to $2700 \mathrm{GtC}$. We assume CO2 emissions of $97.5 \mathrm{~kg}$ per million Btu of coal, $72.6 \mathrm{~kg}$ per million Btu of oil,

\footnotetext{
${ }^{18}$ This amount is based on world GDP as estimated by the World Bank, region-specific capital shares governing the production of the final output, the assumed initial global rental price of capital, and region-specific production of clean energy.
} 
and $53.1 \mathrm{~kg}$ per million Btu of natural gas, which helps us calibrate $\varrho^{M}{ }^{19}$ In calibrating our extraction cost parameters, we assume that the extraction costs double when the available reserves decline by half. This assumption links $\xi_{2}^{M}$ with $\xi_{1}^{M}$ in equation (19). Then, we solve for the values of $\xi_{1}^{M}$ that reproduce the 2017 energy prices under BAU.

The parameters for the climate block of the DICE model (cf. 3.4) are adopted from Folini et al. (2021). ${ }^{20}$ The 2017 land emissions, $E_{t}^{\text {Land }}$, are calibrated at $0.709 \mathrm{GtC}$, and that annual rate of reduction in land emissions, $\delta^{\text {Land }}$, at 0.023 . Radiative forcing in 2017 and $2100, F_{0}^{E X}$ and $F_{1}^{E X}$, are set to 0.5 and 1 , respectively. The radiative-forcing sensitivity parameter, $\eta_{1}$, is set at 3.45. The parameter determining how global mean surface temperature responds to radiative forcing, $\eta_{2}$, is set at 0.137 . Initial values for climate variables are calibrated as $J_{0}^{A}=3116$ GtCO2, $J_{0}^{U}=2804 \mathrm{GtCO} 2, J_{0}^{L}=6596 \mathrm{GtCO} 2, T_{t}^{A}=1.278$ Celsius change since 1900 , and $T_{t}^{L}=0.313$ Celsius change since 1900 . The equilibrium concentration in the atmosphere, $J^{0}$, is set at $607 \mathrm{GtC}$.

Following Folini et al. (2021), the parameter matrices $\Phi^{J}$ and $\Phi^{T}$ are specified as:

$$
\Phi^{J}=\left(\begin{array}{ccc}
0.947 & 0.0536 & 0 \\
0.053 & 0.9422 & 0.0014 \\
0 & 0.0042 & 0.9986
\end{array}\right), \Phi^{T}=\left(\begin{array}{cc}
0.7546 & 0.1 \\
0.0069 & 0.9931
\end{array}\right) .
$$

As for regional damages, we follow Krusell and Smith $\mathrm{Jr}(2018)$ in setting $T^{*}=11.6$ in equation (43). In our most optimistic calibration, $v^{+}=v^{-}=0.001$. Recall, these are damagesensitivity parameters arising from the regional temperature in equation (43).

However, this scenario seems overly optimistic along two dimensions. First, our climate calibration uses the multi-model mean from CMIP5 as a target. However, CMIP5 produces a large range of predictions, and the more pessimistic ones entail much higher temperatures (see Folini et al. (2021)). Moreover, the Krusell-Smith calibration for global damages takes DICE-16 as a benchmark. As Nordhaus (2008) points out, "the economic impact of climate change ... is the thorniest issue in climate-change economics". This is a major and very important theme of Pindyck (2013). Howard and Sterner (2017) conduct a meta-analysis of different global damage functions and argue that the damages might be far larger than assumed in DICE. In our model, damages depend only on the product of the parameter $v$ and $T_{z}-T^{*}$, the regional temperatures in excess of $T^{*}$. Hence, we vary the parameter $\kappa$ to jointly capture different damage functions and degrees of climate sensitivity.

We consider cases with $v^{+}=2 v^{*}, v^{+}=4 v^{*}, v^{+}=6 v^{*}$, where $v^{*}=0.001$ corresponds to the value in the most optimistic calibration. We label these as our $2 \mathrm{x}, 4 \mathrm{x}$, and $6 \mathrm{x}$ cases/scenarios,

\footnotetext{
${ }^{19}$ See https://www.eia.gov/tools/faqs/faq.php?id=73\&t=11 for more details.

20 Dietz et al. (2021), among others, criticize the climate emulators commonly used in economics, including Nordhaus' widely used DICE model (Nordhaus, 2017). A key functionality that any climate emulator needs is to translate anthropogenic emissions, as computed by the economic model, into a global mean temperature change. Emulators typically consist of two parts: The first is a "carbon cycle" that describes how anthropogenic emissions in the wake of human economic activity translate into changes in the CO2 concentration in the atmosphere. The second is a temperature model that determines how the CO2 concentration in the atmosphere translates into an average temperature. The latter, in turn, feeds back again into the economic model. The climate emulator of DICE (cf. section 3.4) in its original formulation, however, does not accord with the latest physical data. Fortunately, the CMIP5 benchmark data. Folini et al. (2021) provide a suite of test cases that permit a full re-calibration of DICE parameters. Compared to the original DICE model, this leads to less long-term warming because of changes in the carbon cycle.
} 


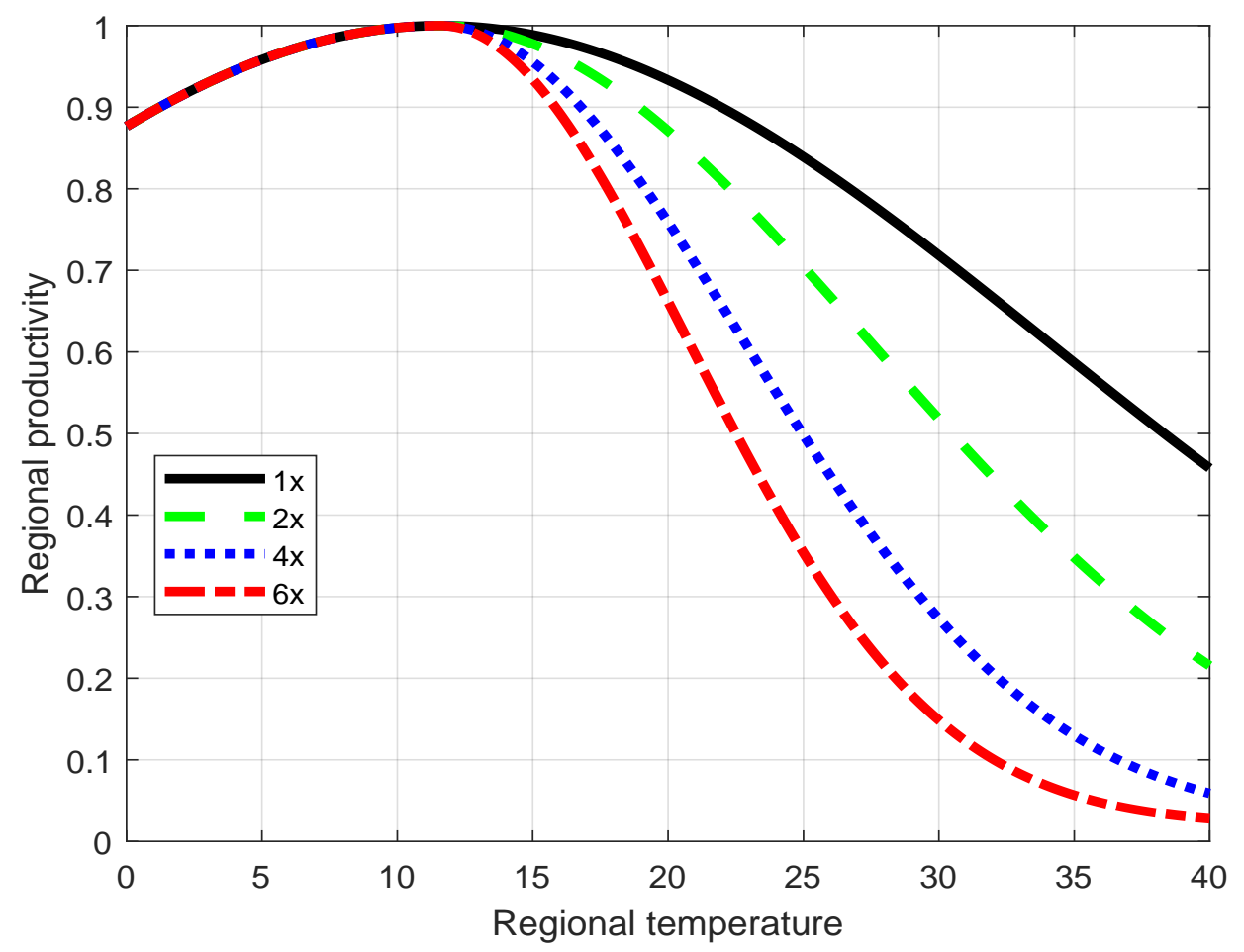

Figure 2: Alternative calibrations of "Krusell-Smith"-type productivity functions as a function of temperature, measured in ${ }^{\circ} \mathrm{C}$.

and reference them as our low-, medium-, and high-damage scenarios. In all cases, $v^{-}$remains fixed at $v^{*}$. Figure 2 depicts the "Krusell-Smith" productivity function (see equation (43)). Note that only the right side of the productivity function shifts. In short, we consider higher damages in regions that incur losses from global warming. At the same time, we assume only moderate gains for regions that incur gains from global warming.

\section{Findings}

This section first presents BAU results for our different damage-function specifications. Next, we consider alternative carbon policies assuming all regions levy annual carbon taxes equal to each year's global SCC. Our "No Transfers" policy taxes carbon but provides no compensation to those suffering welfare losses. Our UWI policy, as indicated, uniformly allocates efficiency gains to all current and future cohorts in all regions. Our UWIF policy reprises our UWI policy but restricts the uniform welfare gains to only future generations; all current generations receive their BAU utility levels. Our fourth policy is UWIL, which, to repeat, runs UWI under the restriction that the lifetime net tax payment of any generation in any region is limited (hence, the L in UWIL) to 10 percent of that region-specific generation's lifetime consumption. We also consider carbon policies that are not Pareto-efficient but that might, nonetheless, arise in the political process. 
Table 5: Peak BAU Losses and Gains (Negative Sign) as Percentage of GDP and Maximal Temperature Increases.

\begin{tabular}{l|rrrr} 
& $1 \mathrm{x}$ & $2 \mathrm{x}$ & $4 \mathrm{x}$ & $6 \mathrm{x}$ \\
\hline US & 4.0 & 7.4 & 12.8 & 17.1 \\
WEU & 1.6 & 2.9 & 4.9 & 6.5 \\
JSHK & 3.9 & 7.1 & 12.4 & 16.7 \\
CHI & 4.0 & 7.4 & 12.7 & 17.0 \\
IND & 11.8 & 21.1 & 34.6 & 43.9 \\
RUS & -4.1 & -4.4 & -4.0 & -3.9 \\
CND & -2.7 & -2.7 & -2.6 & -2.6 \\
EEU & 1.8 & 3.2 & 5.3 & 6.9 \\
SAP & 9.9 & 17.9 & 29.9 & 38.3 \\
BRA & 8.6 & 15.7 & 26.6 & 34.7 \\
MEX & 6.1 & 11.2 & 19.2 & 25.5 \\
SAF & 5.7 & 10.4 & 17.8 & 23.7 \\
MENA & 9.1 & 16.4 & 27.6 & 36.0 \\
SLA & 7.4 & 13.5 & 23.2 & 30.6 \\
SSA & 9.7 & 17.5 & 29.3 & 37.9 \\
SOV & 2.0 & 3.6 & 5.9 & 7.6 \\
GBR & 0.5 & 1.0 & 1.6 & 2.1 \\
ANZ & 4.6 & 8.6 & 14.9 & 19.9 \\
GLOBAL & 4.4 & 7.9 & 13.0 & 16.7 \\
\hline Max. Global Temperature & 4.4 & 4.2 & 3.9 & 3.7 \\
\hline & & & &
\end{tabular}

\subsection{Simulating BAU}

Table 5 reports the maximal BAU increases in global mean temperature (relative to preindustrial levels) as well as peak BAU losses and gains by region for our four damage-function specifications detailed in equation (44). According to our model, absent carbon policy, the planet's average temperature will rise by 3.7 to 4.4 degrees Celsius over the next 200 years. Paradoxically, global mean BAU temperature increases are significantly higher in the (1x and $2 \mathrm{x}$ ) low damage cases because lower damages mean higher GDP and, thus, higher emissions. Despite the higher rise in global temperature, global and regional damages are lower in these cases thanks to their more benign damage functions. Planetary warming under BAU is beneficial to Russia and Canada, whose temperatures rise from between 2.8 and 3.8 degrees and 2.7 and 3.6 degrees, respectively. This reflects their initial (2017) very low average temperatures temperatures that are far too low to achieve peak productivity.

As indicated, damages under BAU can be extraordinarily large for the world as a whole, but particularly for certain regions. For example, in the $6 \mathrm{x}$ scenario, global damages peak at almost 17 percent of world output. However, India's damages reach over 40 percent of GDP by 2200, with this percentage output loss persisting for more than a century. For the US, China, and Japan, the year 2200 damages exceed 16 percent of output with no improvement and, in some cases, a worsening over the following 100 years. GBR experiences the smallest damages, 
peaking at just 2.1 percent of GDP. Russia and Canada's climate gains peak above 3.9 percent and 2.6 percent of GDP, respectively. ANZ, SSA, SLA, SAF, MEX, BRA, MENA, and SAP also experience major damages.

The magnitude of global damages is highly sensitive to the shape of the upper tail of the damage function. In the $6 \mathrm{x}$ case, peak global as well as regional damages are almost four times larger compared to the $1 \mathrm{x}$ parameterization (cf. table 5). Despite the fact that emissions and temperature increases are significantly lower than in the 1x case (again, because of the paradox that higher damages limit output and, thus, emissions), extreme damages in some regions are far larger.

The close-to-20 percent global peak GDP loss in the $6 \mathrm{x}$ case lies well within recent projections of climate damages. Hänsel et al. (2020), for instance, strongly criticizes the DICE damage function, advocating more realistic specifications that lead to much more substantial damages for a 3-degree Celsius or larger increase in temperature. Cruz and Rossi-Hansberg (2021) provide region-specific damage estimates that are roughly in line with our 6x case.

The damage function is just one of many factors that impact the cost of climate change. As indicated, we calibrate our climate emulator according to the multi-model mean of CMIP5 simulations. Calibrating to more pessimistic scenarios would entail both higher temperatures and higher damages, holding the damage function fixed. In addition, the data to which we calibrate may be understating true fossil-fuel reserves, overstating fossil-fuel extraction costs, and suggest faster clean-energy productivity growth than will arise.

Figure 3 compares global CO2 emissions for our 6x BAU scenario over the next 200 years with the emissions projections used in the four RCP scenarios adopted by the Intergovernmental Panel on Climate Change (IPCC) ${ }^{21}$ and the emissions in DICE ${ }^{22}$ As the figure shows, our BAU emissions are significantly lower than in DICE or in RCP8.5. As Hausfather and Peters (2020) point out, RCP8.5 was intended to explore an unlikely high-risk future, entails unrealistically high coal usage. In this light, the RCP6.0 scenario seems more relevant for forecasting emissions absent policy. Our baseline BAU emissions path, which falls between the RCP6.0 and RCP4.5 scenarios, represents a relatively optimistic path.

Under BAU, oil, gas, and coal production definitively ends worldwide in 200 years. ${ }^{23}$ However, dirty energy usage terminates far sooner in some regions. Brazil is the first region to end the use of all fossil fuels in 2045. The US end date of dirty energy usage is 2105. For China, it is 2092 .

\subsection{Carbon Policies}

Table 6 summarizes our key findings. It indicates that optimal initial carbon taxes are extremely sensitive to the damage function. Absent transfers, they range from $\$ 22.8$ per ton CO2 with the $1 \mathrm{x}$ damage specification up to $\$ 111.7$ per ton with $6 \mathrm{x}$ calibration. The corresponding optimal UWI taxes range from $\$ 22.4$ to $\$ 87.5$ under UWI. For a given damage specification, the SCC is higher without net transfers for a simple reason. The net transfers associated with, say, the UWI policy entails significant crowding out of capital thanks to the compensatory transfers made

\footnotetext{
${ }^{21}$ For more details on the IPCC, see ipcc.ch.

${ }^{22}$ For tractability, the figure omits results based on our more benign damage function. Their emissions are, as indicated, slightly higher.

${ }^{23}$ See figures 13,14 , and 15 in the appendix, in which the projected oil, gas, and coal use both under BAU and under the 6x UWI optimal policy is shown.
} 


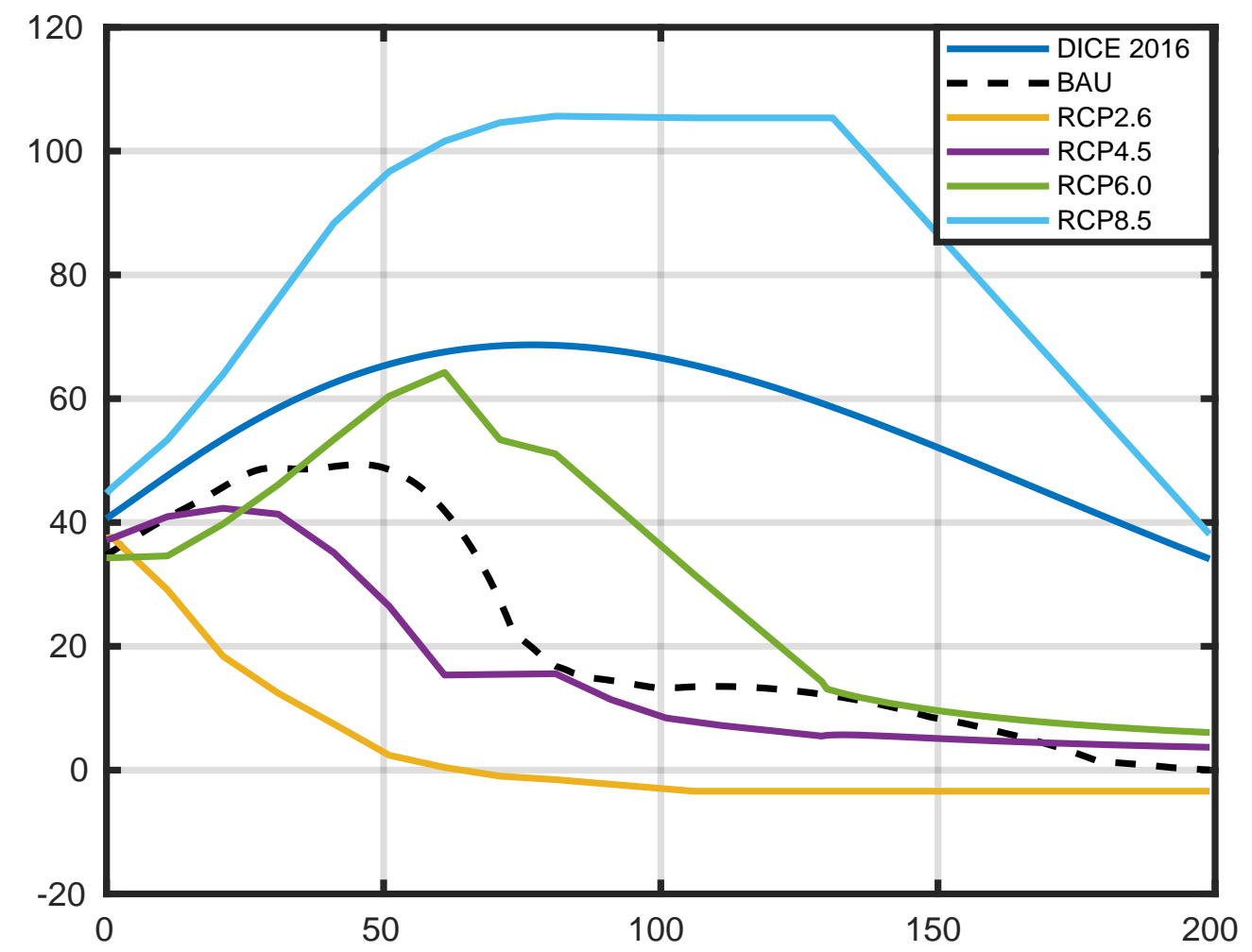

Figure 3: Global CO2 emissions (in GtCO2) in our BAU scenario, DICE 2016, and the different RCP scenarios.

to early generations from their future progeny. In the case of the $6 \mathrm{x}$ damage specification, this raises the global interest rate under UWI by some 100 basis points relative to taxing carbon but not compensating losers. Since the SCC is a discounted sum of marginal future global damages, the higher global interest rate under UWI policy than with no transfers implies, other things equal, a lower SCC and, thus, higher carbon taxes ${ }^{24}$

As indicated, the UWI carbon policy can achieve a major win-win for all humanity. In the 6x UWI case, all generations, present, and future, across all regions gain 4.3 percent. Even in the $4 \mathrm{x}$ case, arguably an optimistic damage scenario, the UWI gain is almost 3.0 percent. Without transfers, some generations incur large welfare losses (up to 18.0 percent) in the $6 \mathrm{x}$ case, while others experience huge gains (up to 47.6 percent).

Maximal global temperature and maximal regional damages are substantially reduced by carbon taxation. However, peak damages are slightly larger with a re-distributive policy than without. Finally, the table shows that the UWI case entails extremely large transfers from future generations in regions hardest hit by climate change. In the 6x case, Indians born in 200 years would be required under UWI policy to surrender more than 45 percent of their consumption to help service outstanding carbon-policy debt. Even in the $2 \mathrm{x}$ and $4 \mathrm{x}$ cases, transfers under the UWI policy are exceptionally large. These findings prompted our consideration of UWIL policy, which, to repeat, caps net taxes on future generations, regardless of region, at 10 percent. Welfare gains are uniform for all region-specific generations not subject to the limit and higher for those subject to the limit. Maximal welfare gains for future generations are 35.6 percent in

\footnotetext{
${ }^{24}$ Tables 8 and 9 in the appendix provide supplementary results on the region-specific SCC for the $6 \mathrm{x}$ specification of the damage function.
} 
Table 6: Key Simulation Results.

\begin{tabular}{|c|c|c|c|c|c|}
\hline Damage case & & $1 \mathrm{x}$ & $2 \mathrm{x}$ & $4 \mathrm{x}$ & $6 \mathrm{x}$ \\
\hline \multirow{4}{*}{$\begin{array}{l}\text { Initial optimal tax, } \\
\$ \text { per ton of } \mathrm{CO} 2\end{array}$} & No Transfers & 22.8 & 43.9 & 80.6 & 111.7 \\
\hline & UWI & 22.4 & 39.3 & 66.4 & 87.5 \\
\hline & UWIF & 22.6 & 42.2 & 75.2 & 101.9 \\
\hline & UWIL & 22.4 & 39.7 & 68.3 & 91.4 \\
\hline \multirow{4}{*}{$\begin{array}{c}\text { Average growth rate of } \\
\text { optimal tax over } \\
\text { the next } 50 \text { years, } \\
\text { percent per year }\end{array}$} & No Transfers & 1.8 & 1.7 & 1.6 & 1.5 \\
\hline & UWI & 1.8 & 1.6 & 1.5 & 1.4 \\
\hline & UWIF & 1.8 & 1.6 & 1.5 & 1.4 \\
\hline & UWIL & 1.8 & 1.6 & 1.5 & 1.5 \\
\hline \multirow{4}{*}{$\begin{array}{l}\text { Welfare gains, } \\
\text { percent }\end{array}$} & No Transfers & $-9.1-8.0$ & $-12.1-16.9$ & $-15.5-34.0$ & $-18.0-47.6$ \\
\hline & UWI & 0.6 & 1.4 & 3.0 & 4.3 \\
\hline & UWIF & $0-0.9$ & $0-2.3$ & $0-5.1$ & $0-7.7$ \\
\hline & UWIL & 0.6 & $1.4-6.2$ & $2.8-22.4$ & $4.0-35.6$ \\
\hline \multirow{5}{*}{$\begin{array}{l}\text { Max. global temperature, } \\
\text { degree Celsius }\end{array}$} & $\mathrm{BAU}$ & 4.4 & 4.2 & 3.9 & 3.7 \\
\hline & No Transfers & 2.8 & 2.5 & 2.2 & 2.1 \\
\hline & UWI & 2.8 & 2.5 & 2.3 & 2.1 \\
\hline & UWIF & 2.8 & 2.5 & 2.2 & 2.1 \\
\hline & UWIL & 2.8 & 2.5 & 2.2 & 2.1 \\
\hline \multirow{5}{*}{$\begin{array}{l}\text { Max. global damages, } \\
\text { percent of global GDP }\end{array}$} & $\mathrm{BAU}$ & 4.4 & 7.9 & 13.0 & 16.7 \\
\hline & No Transfers & 2.5 & 4.1 & 6.7 & 8.9 \\
\hline & UWI & 2.5 & 4.2 & 7.0 & 9.3 \\
\hline & UWIF & 2.5 & 4.2 & 6.8 & 9.1 \\
\hline & UWIL & 2.5 & 4.2 & 6.9 & 9.2 \\
\hline \multirow{5}{*}{$\begin{array}{l}\text { Max. regional damages, } \\
\text { percent of regional GDP }\end{array}$} & $\mathrm{BAU}$ & 11.8 & 21.1 & 34.6 & 43.9 \\
\hline & No Transfers & 7.4 & 12.3 & 20.2 & 26.9 \\
\hline & UWI & 7.4 & 12.6 & 21.0 & 27.8 \\
\hline & UWIF & 7.4 & 12.4 & 20.5 & 27.2 \\
\hline & UWIL & 7.4 & 12.6 & 20.8 & 27.5 \\
\hline \multirow{5}{*}{$\begin{array}{l}\text { Long-run interest rate, } \\
\text { percent per year }\end{array}$} & $\mathrm{BAU}$ & 2.9 & 2.9 & 2.9 & 2.9 \\
\hline & No Transfers & 2.9 & 2.9 & 2.9 & 2.9 \\
\hline & UWI & 3.4 & 3.7 & 4.0 & 4.2 \\
\hline & UWIF & 3.3 & 3.5 & 3.8 & 3.8 \\
\hline & UWIL & 3.4 & 3.7 & 3.9 & 4.0 \\
\hline \multirow{3}{*}{$\begin{array}{l}\text { Minimal regional transfers, } \\
\text { percent of present value of } \\
\text { consumption }\end{array}$} & UWI & -6.7 & -14.6 & -28.8 & -39.9 \\
\hline & UWIF & -6.4 & -14.1 & -27.8 & -38.2 \\
\hline & UWIL & -6.7 & -10.0 & -10.0 & -10.0 \\
\hline
\end{tabular}

IND, 27.2 percent in SAP, 25.2 percent in BRA, 15.5 percent in MEX, 25.9 percent in MENA, 19.5 percent in SLA and 25.9 percent in SSA. We next discuss our 6x results in more detail. 


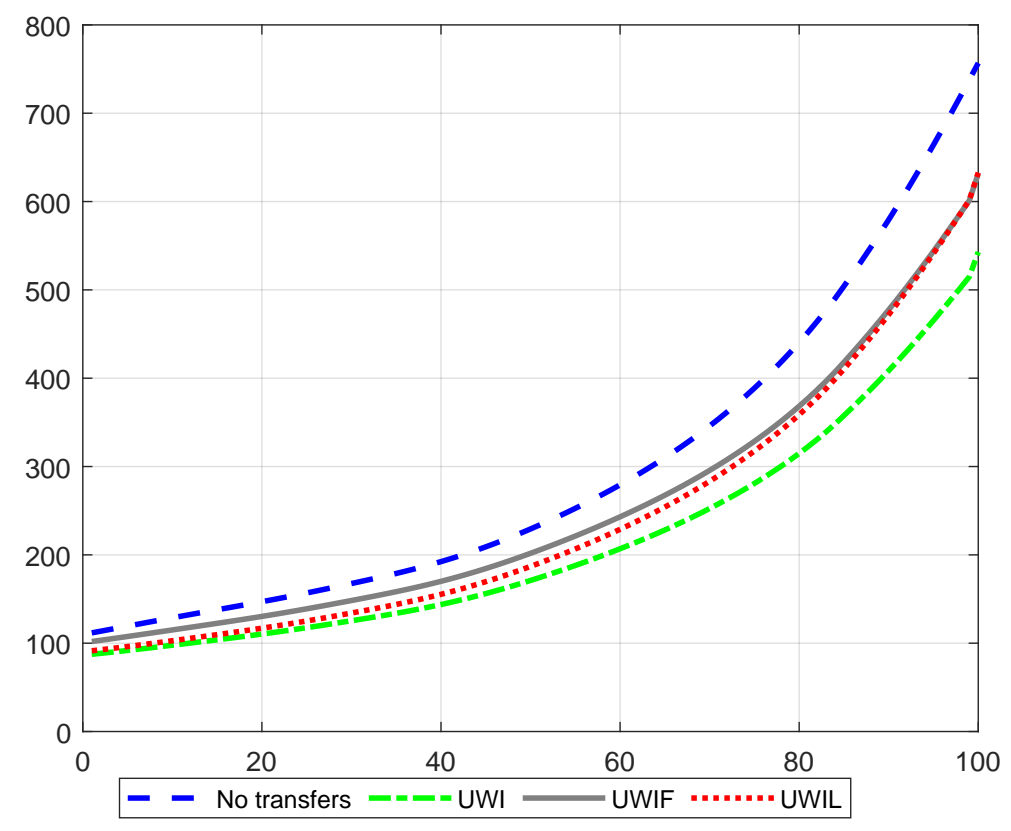

Figure 4: Global Carbon tax under different scenarios, in $\$$ per ton of CO2, and the 6x damage specification as a function of years (starting in 2017).

\subsubsection{Alternative SCC-Determined Carbon-Tax Paths}

Figure 4 shows the SCC-determined carbon taxes for the cases of no transfers, UWI, UWIF, and UWIL. The initial carbon tax and its growth rate is the highest absent transfers. In fact, the carbon tax and, thus, the SCC in year 40 (counting from the year 2017) is almost one-third higher than, for example, under UWI policy. Hence, the choice of SCC-based carbon taxation cannot be determined without deciding whether and how to distribute the efficiency gains from taxing carbon.

In all four cases, SCC-based carbon taxes grow at time-varying rates, with the tax accelerating after 60 years. Optimal taxes 100 years from now are very high - above $\$ 700$ in the no-transfer case. However, the welfare gains from setting a time-varying rather than a fixed growth rate are small, that is, a simple, time-invariant growth in the carbon tax suffices to produce the vast majority of any policy's welfare impacts.

As pointed out in table 6, the average annual carbon-tax real growth rate of the $6 \mathrm{x}$ specification ranges from 1.4 to 1.5 percent. This is in line with Kotlikoff et al. (2021), which featured a 1.5 percent optimal UWI carbon-tax growth rate, albeit in a global, that is, a single-region OLG model. For the 6x case with UWI policy, an initially $\$ 97$ carbon tax growing at 1.5 percent per year, real, also yields a UWI gain of 4.3 percent up to 2 significant digits. One of the reasons for this is that, as we will see now, the high optimal tax for carbon leads to an immediate steep reduction of emissions in almost all regions, and a slight variation in taxes 50 years into the future has almost no effect on cumulative emissions.

Figure 5 shows the $6 \mathrm{x}$ welfare gains and losses for the different tax-transfer schemes.

Absent transfers, many early generations in CHI, IND, RUS, CND, EEU, SAF, MENA, SOV, and GBR, are harmed by SCC-based carbon taxation. Cross-region transfers across contemporaneous generations cannot Pareto improve since there are no welfare gains for generations 

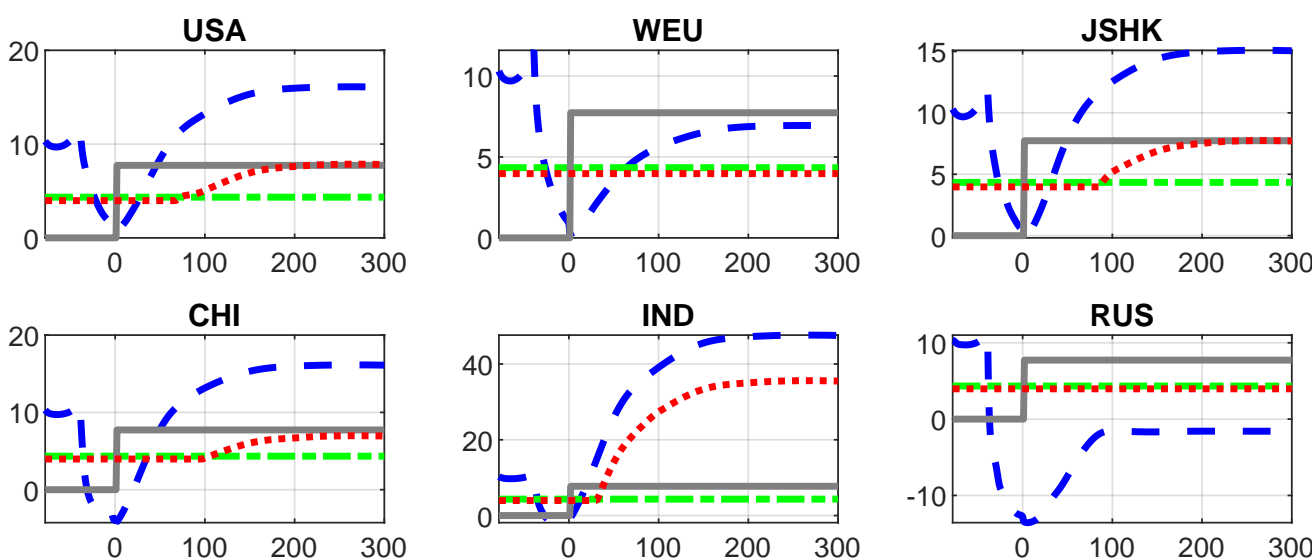

IND

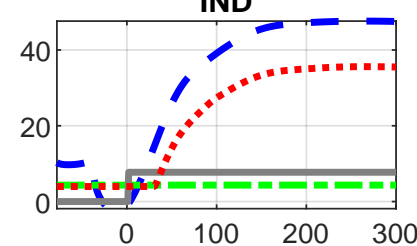

RUS

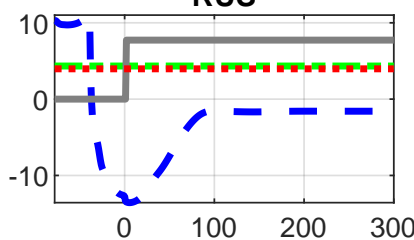

CND

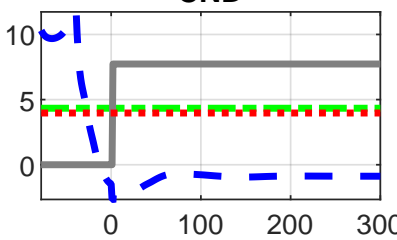

EEU
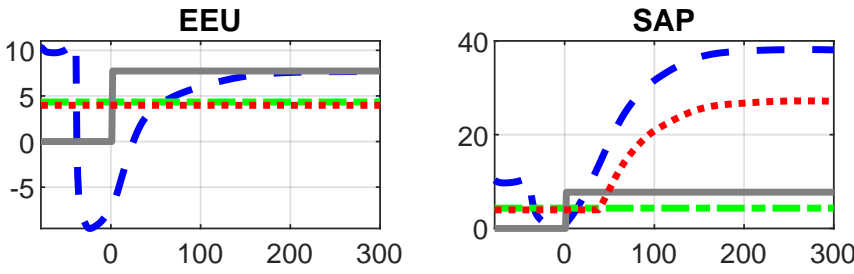

BRA

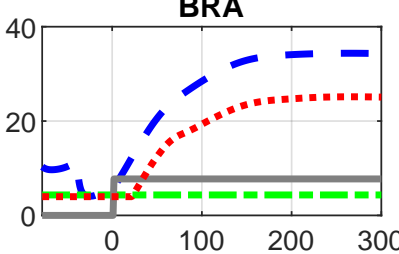

MEX

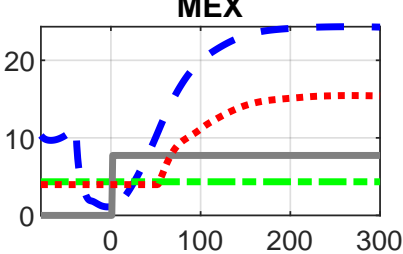

SAF
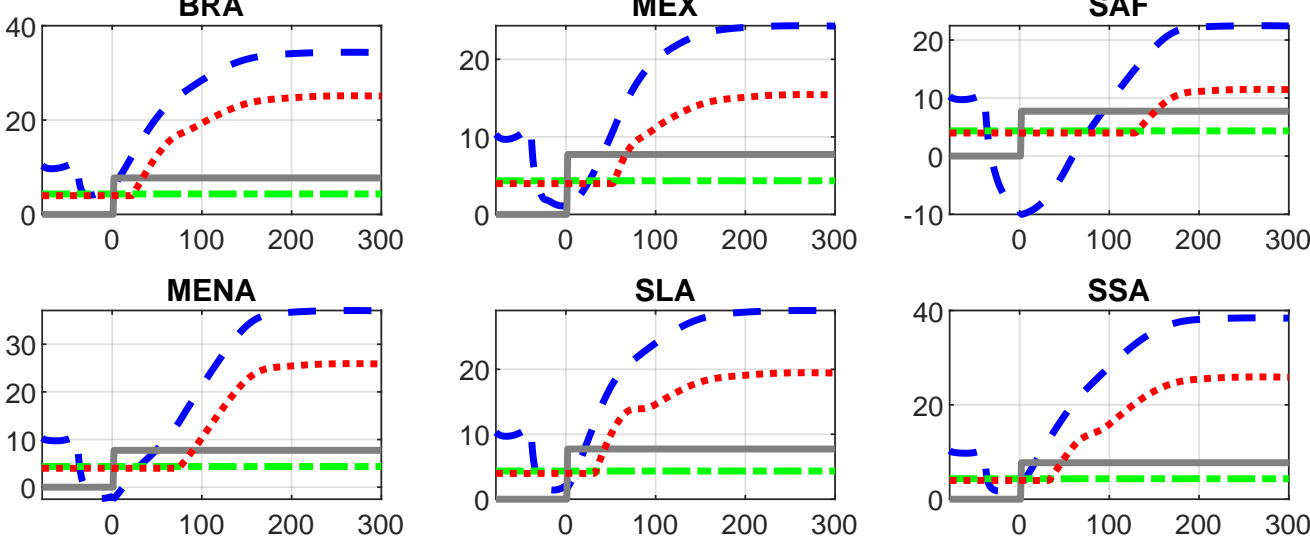

SSA
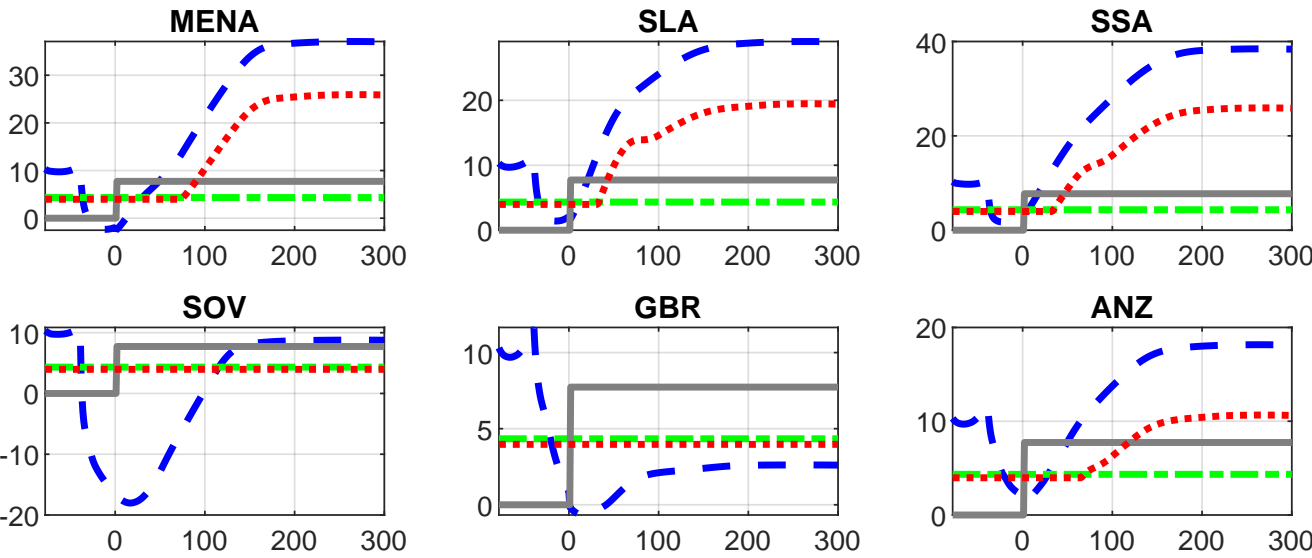

GBR
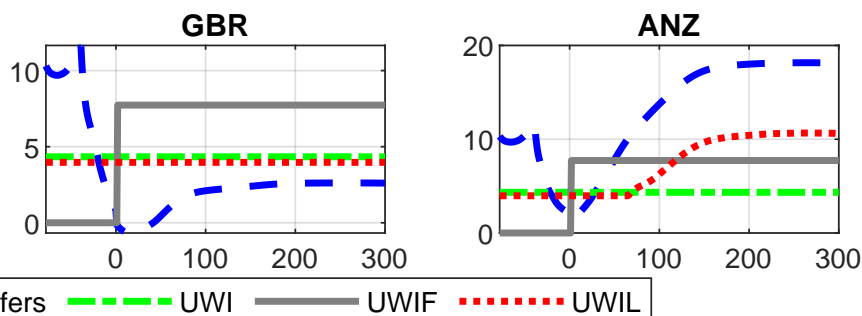

Figure 5: Welfare gains, measured as compensating consumption differentials in percentages.

born around $t=0$. Interestingly, older generations fare better under this policy. The explanation lies in the policy's implicit monopolization of the dirty-energy section, which raises the prices of dirty energy reserves and, for that matter, the value of land used in producing green energy. ${ }^{25}$ However, as indicated in figure 5, there are large welfare gains for many region-specific future

\footnotetext{
${ }^{25}$ Recall, all carbon taxes are lump-sum rebated to the dirty-energy companies, i.e., to their owners, namely initial generations.
} 
generations to be shared. The green line shows the uniform 4.3 percent UWI gain.

Figure 5 s remarkable finding is the closeness of the green and red dotted lines for regions that never hit the limit. The dotted red line is slightly lower - 4.0 percent - under UWIL policy for generations in regions that do not exceed the limit. Other generations in other regions enjoy much larger welfare gains under UWIL. For example, the gain for future Indians peaks at close to 35.6 percent. For future members of SAP, BRA, SSA, and MENA, the peak gain exceeds 20 percent. Even future Americans enjoy far higher welfare gains, that is, roughly twice the UWI level.

The moral here is that by giving up a very small portion of their UWI gain, early generations can dramatically improve the welfare of future generations. Moreover, they can substantially enhance policy compliance as no generation in any region is asked to pay more than 10 percent of their lifetime consumption in net taxes. Paying this net tax will deliver net welfare gains in regions like India that are an order of magnitude larger than their required 10 percent net tax.

\subsubsection{Reductions in Emissions, Temperature, and Damages}

Next, we consider the effects of alternative carbon-tax policies on emissions and damages. We focus again on discussing the $6 \mathrm{x}$ damage specification. The results for the $4 \mathrm{x}$ damage case are similar. However, with even lower damages, optimal carbon taxes are low and, consequently, matter little. Figure 6 depicts the remarkable reduction of emissions in each region arising, in the $6 \mathrm{x}$ case assuming SCC-based carbon taxes. The emissions reductions are very similar and decrease very quickly regardless of the transfer schemes. As figures 13, 14, and 15 in the Appendix show, the different regions stop using dirty energy at very different points in time. China, for instance, stops using all fossil fuels in roughly 20 years compared to 75 years under BAU. Furthermore, Russia stops emitting carbon roughly 80 years earlier than in BAU due to carbon policy. The quick substitution of clean energy, gas, and oil for coal may seem unrealistic. However, such a substitution is arguably already underway in China and other regions, which are rapidly building nuclear power plants while shutting down coal plants. ${ }^{26}$ As table 6 shows, taxing carbon at its marginal social cost dramatically limits the increase in temperature. This is true whether or not compensation is provided. Indeed, the rise in global temperature stays within or near the 2.0-degree limit set in the Paris agreement. Figure 7 shows, for $6 \mathrm{x}$ damages, that carbon taxation, again, no matter the compensation scheme, lowers all regions' temperature paths by roughly the same degree.

Figure 8 shows the extremely heterogeneous nature of climate damages across regions, ranging from very large ones in India to negative ones in Russia and Canada. In addition, the figure also displays the large reduction in economic damages caused by the optimal taxes: The green, optimal 6x UWI carbon-tax damage curves lie below the black BAU curves for all regions but CND and RUS. The different heights of the two curves show that carbon taxation can dramatically reduce regional carbon damage. In some cases, the reduction is by almost 50 percent. For example, in ANZ, maximal damages drop from 20 percent to just above 10 percent, most notably in China, and the US damages drop from above 16 percent to around 8 percent of

\footnotetext{
${ }^{26}$ See, e.g., https://cnpp.iaea.org/countryprofiles/China/China.htm, https://www.forbes.com/ sites/jamesconca/2021/04/23/china-will-lead-the-world-in-nuclear-energy-along-with-allother-energy-sources-sooner-than-you-think, https://world-nuclear-news.org/Articles/Chinastarts-construction-of-demonstration-SMR, or https://www.bbc.com/news/uk-england-somerset58724732 .
} 

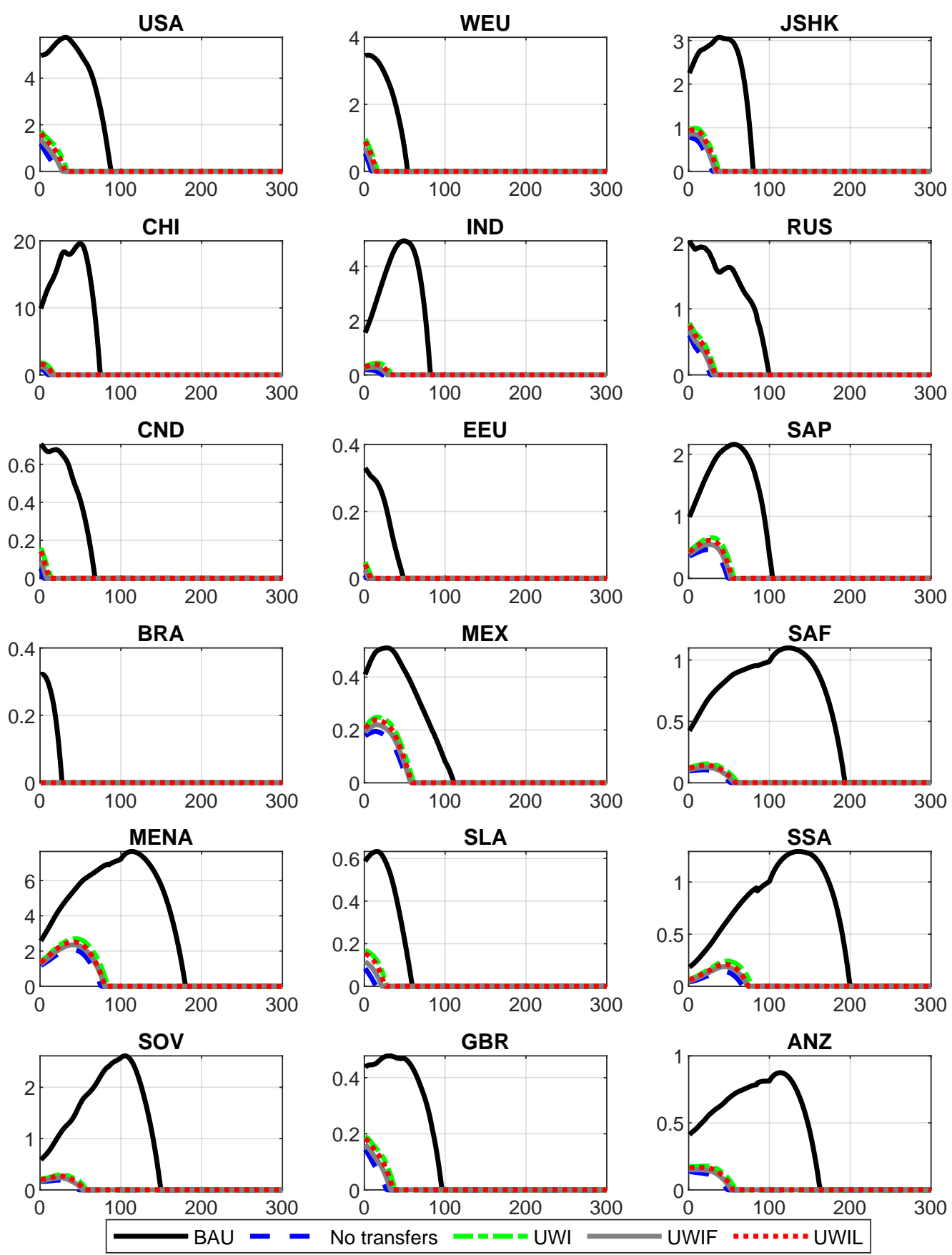

Figure 6: Total CO2 Emissions in the 6x Case (Measured in GtCO2).

GDP.

\subsubsection{Net Transfers}

Optimal carbon taxes are, as indicated, both large and economically important (cf. figure 4 ). They dramatically reduce the use of dirty energy, which materially helps future generations. However, this can require compensating current generations to ensure that they do not incur 

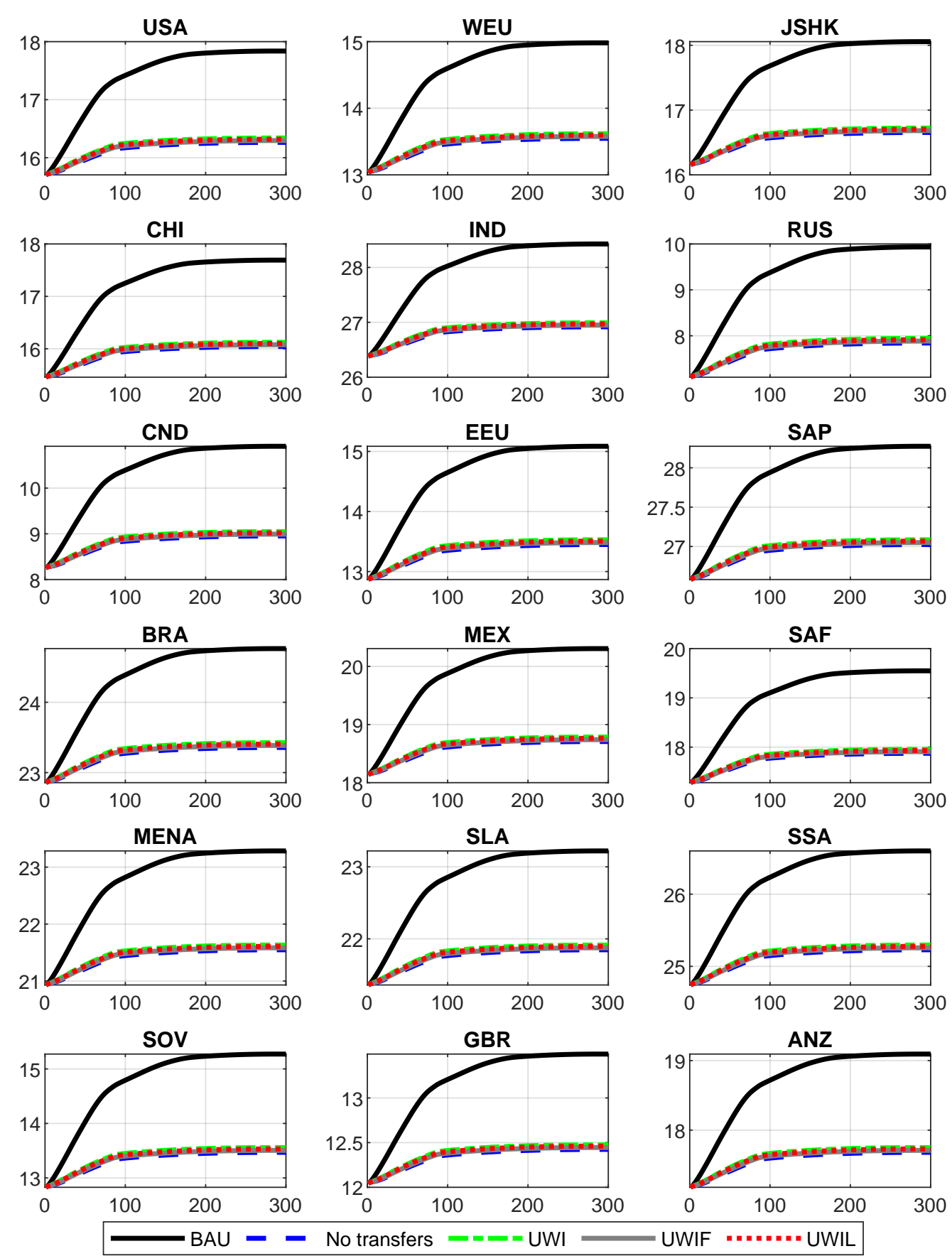

Figure 7: Regional temperature in the $6 \mathrm{x}$ case (measured in ${ }^{\circ} \mathrm{C}$ ).

welfare losses. Figure 9 compares paths of net transfers paid to successive cohorts by year of birth. The horizontal axis specifies the cohort year of birth. ${ }^{27}$ The green dashed line references the UWI policy. The net UWI transfers turn sharply negative for future generations in regions like India, where climate change, absent mitigation, would take the largest toll. For example,

\footnotetext{
${ }^{27}$ For example, a value of -10 on the MENA chart's horizontal axis references the age-30 MENA generation in 2017.
} 



Figure 8: Regional damages in the 6x case (measured as percent of regional GDP).

Indians born in 200 years would be required under the UWI policy to surrender more than 40 percent of their consumption to help service outstanding carbon-policy debt. Other regions with similarly large transfers include BRA, SAP, MENA, SLA, and SSA, whose future generations all need to transfer more than 20 percent of their consumption to other regions and generations.

At first consideration, this sounds extremely onerous and unfair. After all, India is among the world's poorer regions. Why should it be effectively required to subsidize far richer regions, like the US (whose long-run net tax is much smaller), who are causing a much larger share of 
the global externality? The answer is that adhering to this policy will benefit Indians, including all future Indians, to the same degree as it benefits those in the richest regions. It is important to bear in mind that, thanks to the global carbon tax, future Indians will be paying a high net tax rate on a far larger level of consumption than would otherwise be the case. While fairness is not the issue, the UWI policy is unfortunately extremely unlikely to succeed. While future Indians today would agree on a contract that costs them 30 percent of lifetime consumption in exchange for optimal carbon taxes, come the year 2120, young Indians have absolutely no incentives to keep the contract. The vast literature on sovereign debt (e.g., Eaton and Fernandez (1995)) and the vast number of cases of sovereign default clearly shows that the enormous debt levels required by our UWI policy in the $6 \mathrm{x}$ case are not sustainable.

Therefore we consider our third efficient policy that caps tax rates at 10 percent for all regions and all future generations. The red dotted line shows transfer payments for this almost uniformly welfare-improving policy. This is arguably the policy with the largest chance of political support, both by current generations and future generations.

One needs to keep in mind that all carbon tax revenues are distributed among the currently alive; that is, these transfers are not included in figure 9 which explains why in the "Unborn" scenario, currently old agents need to make transfers to future generations. It also explains why there are large wiggles around time $t=0.28$

Surprisingly, although maximal transfers for this policy are much smaller than for UWI, the welfare gains guaranteed for all generations and regions are almost as large. As depicted in figure 6, all generations in all regions gain at least 4.0 percent (as opposed to 4.3 percent in the full UWI case). Naturally, future generations in regions hit hardest by climate change gain much more, with future generations in India gaining almost 40 percent.

Since overall transfers are smaller than in the UWI case, the increase in the interest rate is also less pronounced, and hence optimal taxes are higher than in UWI. More details are shown in Figure 4 .

\subsection{Inefficient Policy}

Pareto-optimal taxes require large inter-regional and intergenerational transfers and, absent transfers, significant welfare losses for current generations. It is all but clear how to enforce them globally. After all, climate change action is a classical free-rider problem. If one relatively small region does not participate and imposes no carbon tax, the overall reduction in $\mathrm{CO} 2$ emissions and future damages will be largely unaffected. Therefore, the region has no incentive to participate even if it expects large future damages in the BAU scenario.

The subsequent sections 5.3 .1 and 5.3 .2 discuss how outcomes differ if global participation does not materialize, leaving single regions or subsets of regions to implement their own UWI carbon policies.

\footnotetext{
${ }^{28}$ In some regions, such as GBR, there are also wiggles at future dates. They are fully consistent with each generation in each region experiencing a precisely identical UWI. They reflect discontinuous region-specific changes in demographics, changes through time in fossil fuel stock market values, and changes through time in carbon-tax revenue compensation to fossil fuel companies.
} 

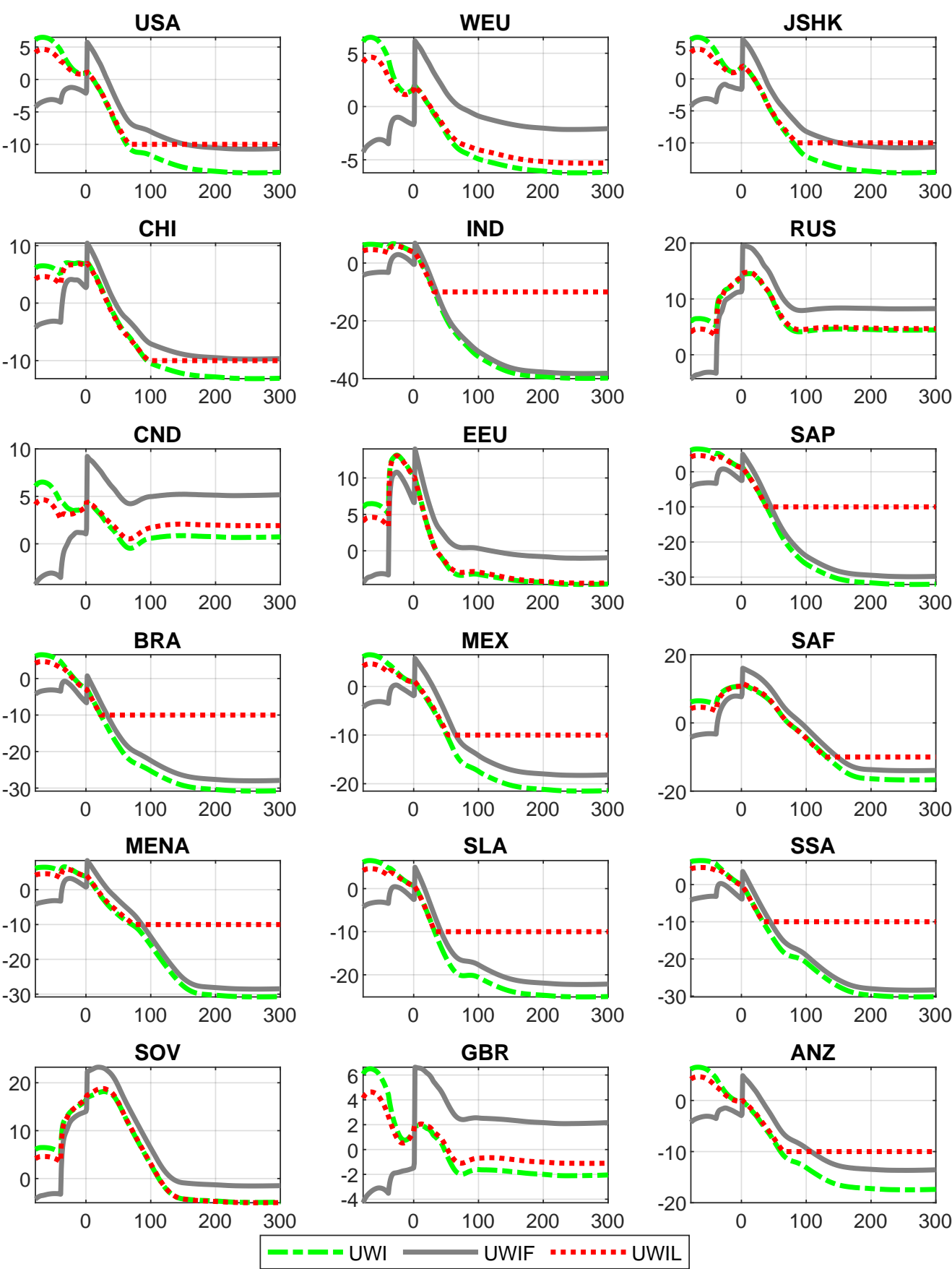

Figure 9: Net transfers as a share of the remaining or full lifetime consumption in the $6 \mathrm{x}$ case (year 0 is 2017).

\subsubsection{Partial International Participation}

How do our results change if we assume that only some regions introduce a carbon tax? In considering carbon tax policy in a given subset of regions, we tax the use of dirty energy in all subset regions but now redistribute all carbon-tax revenues to households in participating regions in proportion to their populations. Figure 10 shows the effect of a regional $\$ 100$ carbon tax on global emissions. In addition to a global tax, we also consider a tax only in CHI, JSHK, 


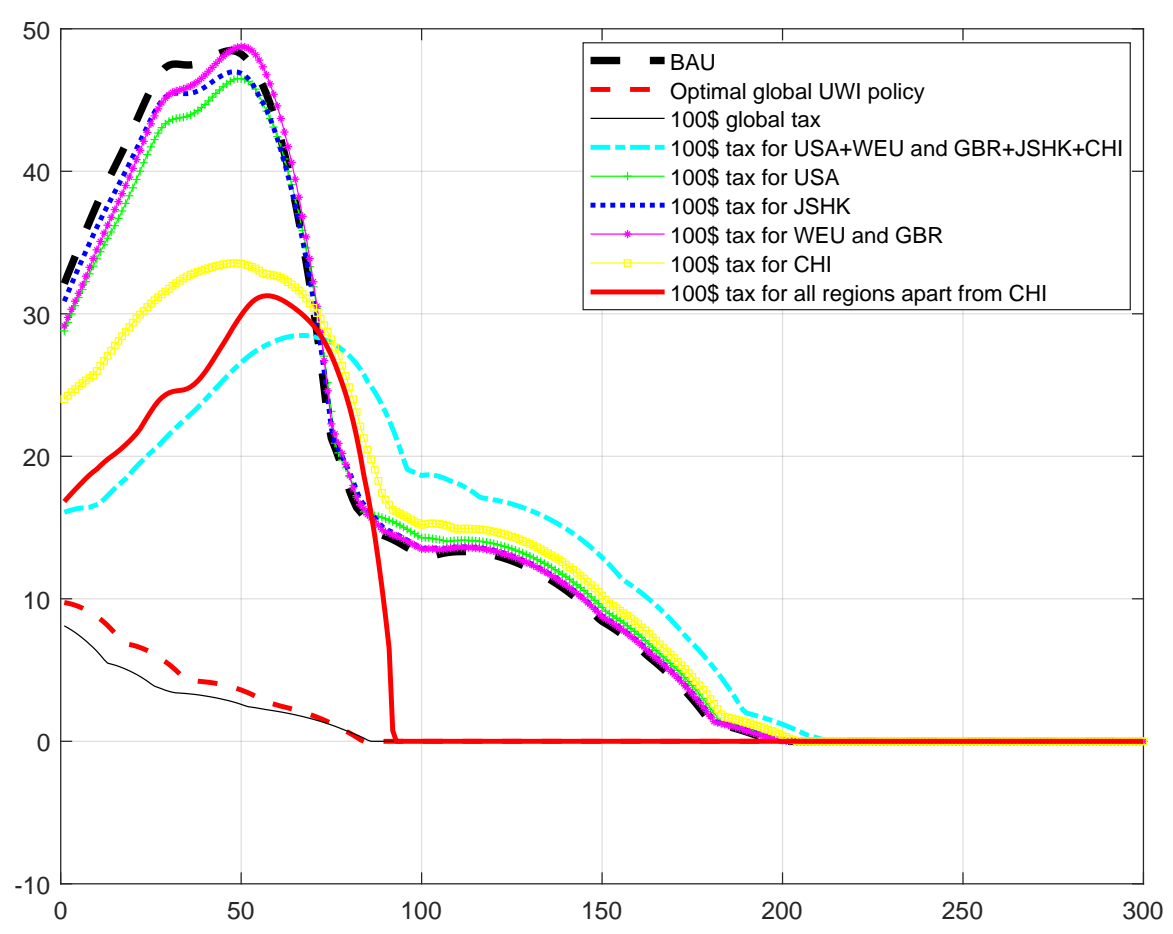

Figure 10: Global CO2 emissions (absent of land emissions, and measured in GtCO2) in the 6x scenario under alternative coalitions as a function of years (starting in 2017).

GRB, WEU, and the US and taxes only in the US, only in CHI, only in JSHK, and only in WEU and GBR. As the figure shows, taxes levied in only a single region have limited effects, even if that region is China. A $\$ 100$ Chinese-only carbon tax, with a 1.5 percent growth rate, lowers initial global emissions by roughly one-sixth. In contrast, a $\$ 100$ carbon tax, growing at 1.5 percent annually but levied only in the US, only in Western Europe, or only in JSHK, has almost no effect on global emissions. The larger Chinese impact reflects China's coal-intensive technology for producing dirty energy.

Given the relatively small impact of a large regional tax on emissions and warming, the issue of partial participation is clearly problematic. If one hopes for regional welfare gains from optimal regional taxes and transfers, one is easily disappointed. Tables 8 and 9 in the Appendix illustrate the problem by reporting regional SCC for different regions and different years. For the 6x BAU case, this regional SCC is only significant in China and the US. Despite the fact that damages are projected to be very large in regions like India and Brazil, the 2017 SCC for India is only about $\$ 10.50$, for Brazil, only $\$ 3.12$. The global SCC, in this case, is $\$ 111.69$. As one would expect from these numbers, it turns out that only one partial coalition - all regions apart from China - appears capable of producing a positive welfare gain for its members. For example, a $\$ 100$ carbon tax, approximately equal to the global SCC, levied by all regions apart from China and grown annually at 1.5 percent produces a 1.5 percent UWI gain for coalition members.

We also considered coalitions that tax themselves not based on the global SCC but only on their collective local SCC. They redistribute among themselves to achieve a uniform welfare gain among all members. In this case, there are three coalitions with positive welfare gains: UWI gains equal to 1.6 percent for all regions apart from CHI. The equal 0.9 percent for a 
coalition consisting of the US, WEU, GBR, JSHK, and CHI. They equal only 0.3 percent for a coalition consisting solely of CHI.

The inability of subsets of regions to get close to the joint global optimum reflects, in large part, general equilibrium effects. When one region or a subset of regions impose carbon taxes, they drive down the price of dirty energy. This, in turn, leads non-participating regions to increase their use of fossil fuels. This Black Paradox is akin to the "Green Paradox" discussed below in section 5.3.2. The bottom line here is clear. Carbon taxation needs to be global to be effective.

\subsubsection{Delaying Carbon Taxation and the Green Paradox}

A major concern with carbon policy is its timing. As Sinn $(1982)$ points out, announcing the implementation of a carbon tax in advance will alert dirty-energy producers to "use it or lose it". Of course, speeding up the burning of fossil fuels will accelerate climate change relative to BAU - hence the term Green Paradox. The problem is lessened when, as in our model, there is costly dirty-energy extraction. However, a delay in our model also comes at a cost. Indeed, postponing the implementation of the optimal UWI tax until 2040, taking into account its growth, reduces the $1 \mathrm{x}$ UWI gains from 0.6 to 0.5 percent. In the $2 \mathrm{x}$ case, they drop from 1.4 to 1.0 percent. In the $4 \mathrm{x}$ case, the decline is from 3.0 to 2.0 percent. Furthermore, in the $6 \mathrm{x}$ case, the reduction is from 4.3 to 2.8 percent. A delay reduces maximum UWI gains and increases emissions during the period of the delay, not only relative to immediate policy implementation, but relative to engaging in no policy. For example, 2030 carbon emissions are 13.4 percent higher than under BAU in the $6 \mathrm{x}$ case.

What if all regions but China immediately adopt a carbon tax, but China waits 20 years? ${ }^{29}$ Our computations show that this lowers the UWI gain from 4.3 percent to 3.8 percent in the $6 \mathrm{x}$ case. In the $4 \mathrm{x}$ case, China's delayed participation reduces the UWI gain from 3.0 percent to 2.7 percent. Moreover, in the $2 \mathrm{x}$ and $1 \mathrm{x}$ case, the UWI gains are virtually unaffected by a Chinese delay in joining all other regions in taxing carbon.

\section{Conclusion}

Climate policy is generally viewed as a zero-sum game pitting future against current generations and regions that benefit from climate change against regions that do not. As our study shows, the difference in interests across generations and regions run deep. Potential BAU losses to future generations in most regions are strikingly large. Indeed, absent policy, climate change produces peak GDP regional losses under our high but not unreasonable cost scenario, ranging from 17 to over 40 percent in 12 of our model's 18 regions. Peaks losses for India reach 43.9 percent. They exceed 30 percent for SSA, SLA, MENA, BRA, SAP, and IND. For the US, losses peak at 17.1 percent. In contrast, for Russia and Canada, climate change is good news. Under BAU, Russia's and Canada's peak output gains are 3.9 percent and 2.6 percent, respectively.

Yet, simply imposing a carbon tax equal, through time, to carbon's marginal global intertemporal damage (the so-called social cost of carbon) will harm early generations. For example, these welfare losses equal 10.1 percent for those born in 2017 in SAF, 13.6 percent for those

\footnotetext{
${ }^{29}$ Chinese generations born after that receive transfers to ensure that they get the same uniform welfare gains as the rest of the world.
} 
born in 2021 in RUS, 9.5 percent for those born in 1993 in EEU, and 18.0 percent for those born in 2033 in SOV.

Fortunately, there is a mutually beneficial solution to this seemingly insurmountable conflict of interests. We show that a compensatory carbon-tax policy can achieve a win-win for all cohorts regardless of their place or time of birth. Indeed, carbon taxation coupled with regionand generation-specific positive or negative transfers can achieve a uniform welfare gain, that is, an identical percentage improvement in economic well-being for all. Our calculated optimal UWI (uniform welfare improving) gain is 4.3 percent, measured as a consumption-equivalent. This policy is effected by a) levying an annual global carbon tax equal to the contemporaneous social cost of carbon, b) making transfers to cohorts that would otherwise gain less than 4.3 percent, and c) taxing cohorts that would otherwise gain more than 4.3 percent. Those receiving transfers include both Russians and Canadians, for whom climate change represents a positive externality, and early cohorts in most regions, that is, cohorts born too soon to benefit from climate change's mitigation, yet stuck paying higher energy prices. Those paying taxes are future generations in regions otherwise harmed, and potentially greatly so, by climate change.

Having each region impose, through time, the global carbon tax is one thing. However, what institution would oversee the win-win redistribution mechanism? One answer is the International Monetary Fund, which could issue green bonds to finance, in the short run, requisite transfers, while servicing these bonds over time with region- and cohort-specific taxes. However, the redistributive aspect of UWI policy may be unenforceable due to very high taxes required of future cohorts in a number of regions. Future Indians, for example, face net taxes equal to 40 percent of their lifetime consumption. Although these taxes and those of other future cohorts are needed to service the green bonds, future generations may fail to do so since the planet's overheating has already been averted.

To mitigate this time consistency problem, we explored UWIF policy, that is, UWI policy, but with the uniform welfare gain restricted to future generations. Current generations are left with their BAU levels of utility. UWIF policy provides all next generations with a 7.7 percent welfare gain. Furthermore, it limits the taxes they face to service the now smaller issuance of green bonds. However, their projected tax bill remains extremely high, especially for Indians. Indians born in 2200, for example, pay the equivalent of 38.2 percent of lifetime consumption in taxes. This is only slightly lower than the 39.9 percent under UWI.

Our third policy - UWIL - significantly lessens the time-consistency problem. It provides a uniform welfare gain to all cohorts in all regions apart from cohorts who would otherwise pay taxes exceeding 10 percent of their lifetime consumption. Taxes on such cohorts are limited to this 10 percent level, meaning they enjoy a higher welfare gain than under UWI policy. Importantly, UWIL still delivers major welfare gains, namely 4.0 percent for all cohorts under the tax limit and far higher for cohorts at the tax limit. For example, Indians born in the long run experience a 35.6 percent welfare gain, which is dramatically higher than the gains under UWI or UWIF policy.

For our high-damage case, the UWIL carbon tax starts at $\$ 91.4$ per ton of CO2, rising, in real terms, at roughly 1.5 percent per year. This policy dramatically reduces global and region-specific climate damage. It also materially shortens the duration of fossil-fuel usage by roughly 130 years. Rather than increasing by as much as 3.7 degrees Celsius under BAU, the peak temperature rise under UWIL policy is 2.1 degrees. Peak global damages under UWIL are 9.2 percent of the planet's GDP. For India, the worst-hit region under BAU, damages peak 
at 27.5 percent of GDP under UWIL versus 43.9 percent under BAU.

Thus, a realistic, Pareto-improving carbon policy that makes all of humanity better off by at least 4 percent can make a major contribution to our planet's future. This said, two factors are critical. The first is China's participation, given its massive current and projected future carbon emissions. China's failure to participate reduces the potential Pareto gains in our high-damage calibration by almost two-thirds. The second is immediate policy implementation. Waiting until 2040 to tax carbon, even at the rate that would otherwise be implemented under an optimal policy, reduces the potential Pareto gains by about one-third. 


\section{Appendix A Supplementary Materials}

Appendix A.1 contains supplementary material for the calibration outlined in section 4, whereas appendix A.2 complements the results from section 5. Moreover, appendix A.3 examines whether carbon-tax policy matters for the evolution of global economic power. Finally, appendix A.4 provides more details on the computation.

\section{A.1 Calibration}

Table 7 reports GDP, energy consumption, and CO2 emissions by region relative to the US. Figure 11 reports UN-projected demographics in the 18 regions. Projected population declines in almost all regions, with the only exceptions being the US, CND, SSA, and ANZ; it is projected to increase over the next 100 years and then remain constant. The wiggles in some of these graphs come directly from the UN data. Figure 12 compares aggregate BAU damages resulting from our $1 \mathrm{x}$ specification of the damage function to aggregate damages predicted by DICE (Nordhaus, 2017). It can be seen that predicted damages are similar in both specifications.

Table 7: 2017 GDP, Energy Consumption, and CO2 Emissions Relative to the US.

\begin{tabular}{c|ccc} 
& GDP index & Energy consumption index & CO2 emission index \\
\hline ANZ & 7.85 & 7.16 & 8.41 \\
BRA & 10.57 & 12.87 & 10.28 \\
CND & 8.47 & 15.41 & 12.01 \\
CHI & 62.29 & 142.65 & 195.75 \\
EEU & 1.33 & 5.89 & 5.96 \\
GBR & 13.70 & 8.41 & 7.75 \\
IND & 13.60 & 31.18 & 42.79 \\
JSHK & 36.28 & 37.75 & 44.67 \\
MENA & 21.65 & 56.05 & 60.74 \\
MEX & 5.95 & 8.09 & 8.75 \\
RUS & 8.11 & 33.59 & 34.30 \\
SAF & 1.80 & 5.81 & 8.81 \\
SAP & 12.83 & 20.81 & 24.69 \\
SLA & 10.72 & 15.79 & 14.52 \\
SOV & 1.85 & 9.06 & 10.53 \\
SSA & 5.13 & 4.94 & 4.90 \\
US & 100.00 & 100.00 & 100.00 \\
WEU & 81.79 & 67.98 & 63.20 \\
\hline
\end{tabular}

\section{A.2 Additional Findings}

Tables 8 and 9 depict the region-specific social costs of carbon for the $6 \mathrm{x}$ specification of the damage function. The optimal case refers to the UWI policy. Obviously, the SCC is high for regions with high total GDP, notably CHI and USA. Note that in the optimal cases, the tax on carbon equals the SCC.

Figures 13, 14, and 15 depict projected oil, gas, and coal use both under BAU and under the 6x UWI optimal policy. The dramatic effect of the taxes on coal use is notable. 

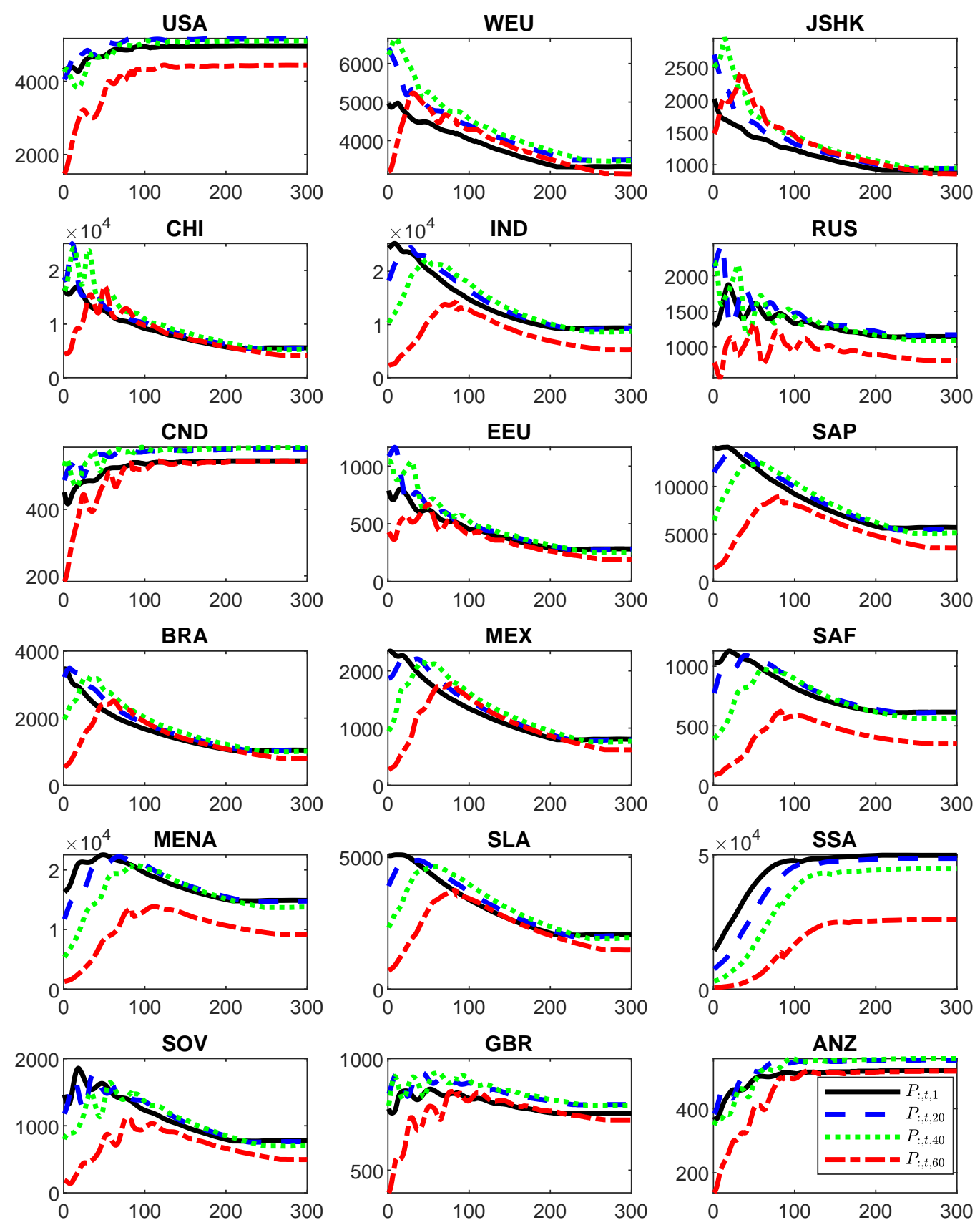

Figure 11: Projected Population (in millions) of Specified Age Groups

\section{A.3 Carbon Policy and the Future of Economic Power}

Table 10 examines, for the 6x scenario, whether carbon-tax policy matters for the evolution of global economic power.

The answer is no and yes. First, with or without a carbon policy, China is projected to eclipse the US economically. In 2100, the US accounts for only 15.5 percent of global output compared with 25.0 percent in 2017. In contrast, China's share of world output grows from 15.6 percent in 2017 to 32.6 percent in 2100 . However, the end of the US economic hegemony 


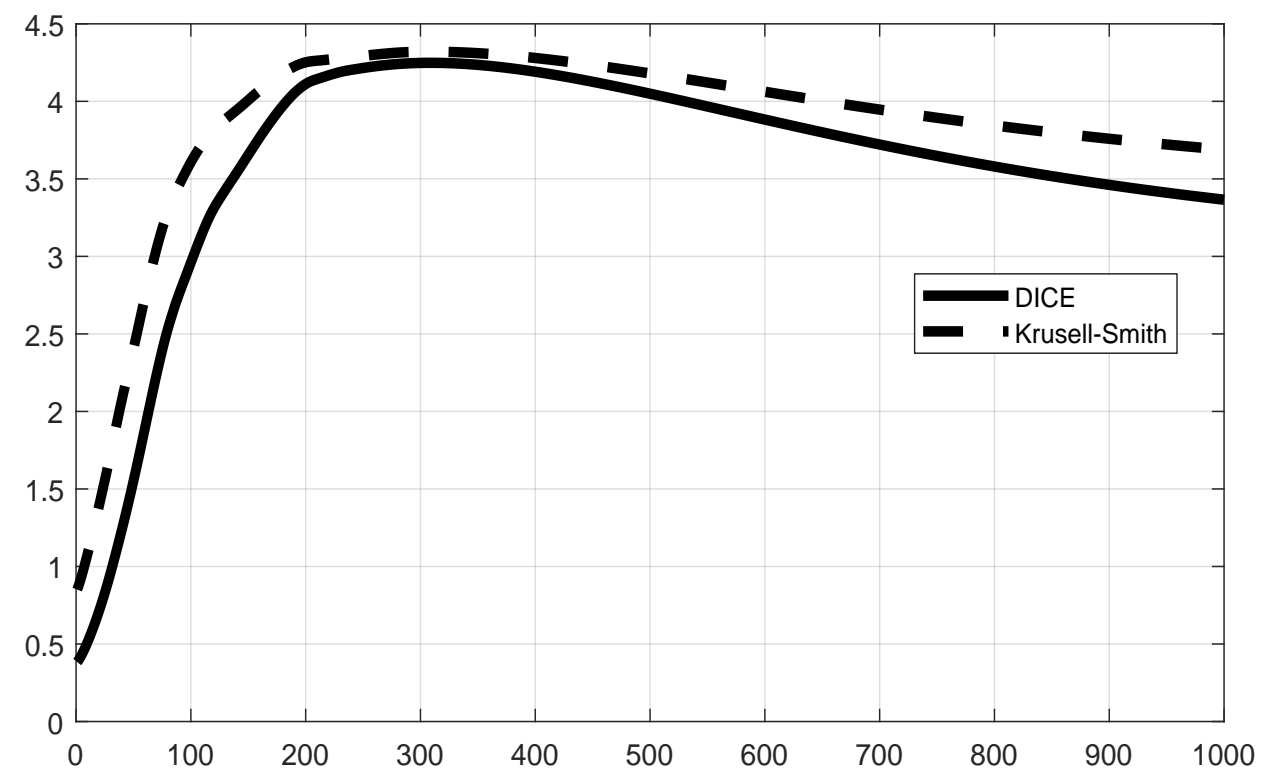

Figure 12: Comparing the "DICE" and "Krusell-Smith"(cf. equation (44)) global damages as share of global GDP (measured in \%) by year (starting 2017).

and the path to that end is essentially invariant to carbon policy. This reflects the roughly equal proportionate $6 \mathrm{x}$ climate losses experienced, through time, by both the US and China ${ }^{30}$ Interestingly, the US drops to third place, leaving Western Europe (WEU plus GBR) with silver.

Absent carbon policy, Western Europe's global GDP share, which is 3 percentage points less than the US share in 2017, surpasses the US share by almost 1.5 percentage points by century's end. This gap drops to roughly half with carbon policy and reflects the relative importance of carbon policy to the US compared to Western Europe, indicated in table 5. India, which stands to lose the most from climate change, is another example of carbon policy's potentially significant, if hardly overwhelming, impact on the share of global GDP. In 2100, India's share of world output is 6.43 percent with UWI policy, but 5.38 percent without.

${ }^{30}$ See table 5 in the main part of the paper. 

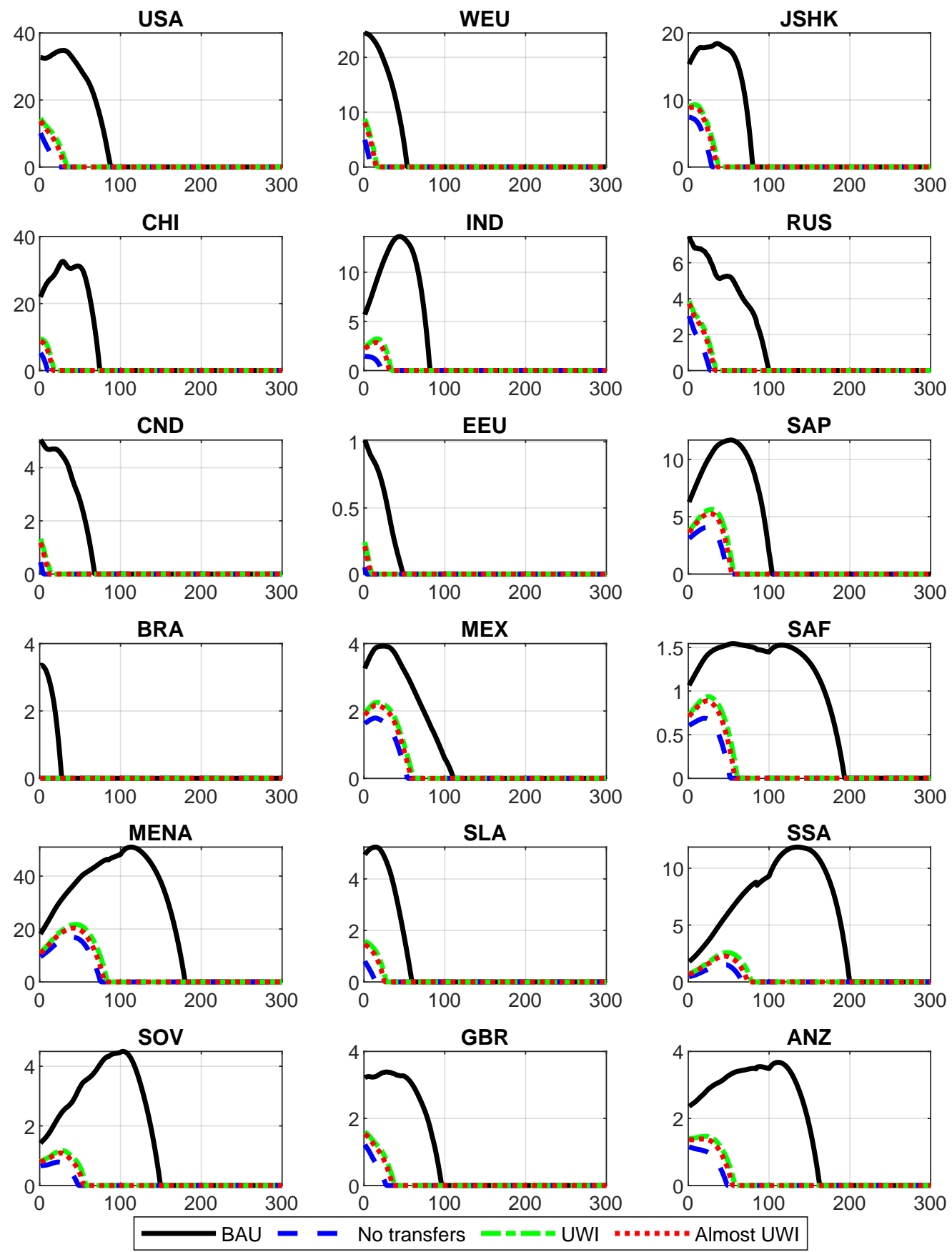

Figure 13: Oil consumption in the 6x case (measured in quad Btu) 
Table 8: Social Cost of Carbon, $\$$ per Ton of CO2, Part 1.

\begin{tabular}{|c|c|c|c|c|c|c|c|c|c|}
\hline & USA & WEU & JSHK & $\mathrm{CHI}$ & IND & RUS & CND & EEU & SAP \\
\hline \multicolumn{10}{|c|}{$1 \mathrm{x}$ case, $\mathrm{BAU}$} \\
\hline 2017 & 3.95 & 1.44 & 2.04 & 5.05 & 3.47 & -0.22 & -0.18 & 0.01 & 1.72 \\
\hline 2025 & 4.53 & 1.70 & 2.42 & 6.17 & 4.23 & -0.21 & -0.18 & 0.02 & 2.00 \\
\hline 2050 & 6.16 & 2.63 & 3.83 & 10.37 & 6.60 & -0.16 & -0.13 & 0.02 & 2.72 \\
\hline 2100 & 16.56 & 8.26 & 12.98 & 36.72 & 18.66 & -0.17 & -0.06 & 0.05 & 6.35 \\
\hline \multicolumn{10}{|c|}{ 1x case, optimal } \\
\hline 2017 & 3.84 & 1.27 & 1.98 & 4.71 & 3.61 & -0.24 & -0.23 & 0.01 & 1.80 \\
\hline 2025 & 4.37 & 1.48 & 2.35 & 5.74 & 4.42 & -0.24 & -0.24 & 0.01 & 2.12 \\
\hline 2050 & 5.95 & 2.23 & 3.74 & 9.76 & 7.17 & -0.23 & -0.26 & 0.02 & 3.01 \\
\hline 2100 & 15.71 & 6.71 & 13.01 & 35.95 & 22.18 & -0.44 & -0.54 & 0.04 & 7.50 \\
\hline \multicolumn{10}{|c|}{$2 \mathrm{x}$ case, $\mathrm{BAU}$} \\
\hline 2017 & 7.83 & 2.94 & 4.06 & 10.02 & 6.02 & -0.23 & -0.19 & 0.03 & 3.09 \\
\hline 2025 & 8.91 & 3.46 & 4.79 & 12.17 & 7.25 & -0.22 & -0.19 & 0.03 & 3.56 \\
\hline 2050 & 11.99 & 5.30 & 7.50 & 20.21 & 11.03 & -0.17 & -0.15 & 0.04 & 4.72 \\
\hline 2100 & 31.79 & 16.45 & 25.03 & 70.37 & 30.17 & -0.20 & -0.12 & 0.09 & 10.72 \\
\hline \multicolumn{10}{|c|}{$2 \mathrm{x}$ case, optimal } \\
\hline 2017 & 6.97 & 2.25 & 3.50 & 8.12 & 5.86 & -0.25 & -0.23 & 0.02 & 3.09 \\
\hline 2025 & 7.78 & 2.57 & 4.06 & 9.72 & 7.05 & -0.25 & -0.25 & 0.02 & 3.56 \\
\hline 2050 & 10.07 & 3.67 & 6.21 & 15.99 & 11.09 & -0.24 & -0.27 & 0.03 & 4.86 \\
\hline 2100 & 24.13 & 10.17 & 20.47 & 56.53 & 32.68 & -0.43 & -0.54 & 0.06 & 11.35 \\
\hline \multicolumn{10}{|c|}{$4 \mathrm{x}$ case, $\mathrm{BAU}$} \\
\hline 2017 & 15.29 & 6.09 & 7.97 & 19.66 & 9.15 & -0.24 & -0.21 & 0.06 & 5.00 \\
\hline 2025 & 17.17 & 7.10 & 9.29 & 23.54 & 10.78 & -0.24 & -0.21 & 0.06 & 5.64 \\
\hline 2050 & 22.62 & 10.68 & 14.25 & 38.22 & 15.64 & -0.19 & -0.18 & 0.08 & 7.17 \\
\hline 2100 & 58.56 & 32.39 & 46.41 & 129.31 & 40.88 & -0.27 & -0.22 & 0.18 & 15.63 \\
\hline \multicolumn{10}{|c|}{$4 \mathrm{x}$ case, optimal } \\
\hline 2017 & 12.62 & 4.08 & 6.17 & 14.01 & 8.73 & -0.25 & -0.24 & 0.04 & 4.90 \\
\hline 2025 & 13.73 & 4.51 & 6.97 & 16.36 & 10.29 & -0.25 & -0.26 & 0.04 & 5.52 \\
\hline 2050 & 17.07 & 6.17 & 10.32 & 26.29 & 15.81 & -0.24 & -0.29 & 0.05 & 7.32 \\
\hline 2100 & 38.11 & 16.14 & 33.03 & 91.27 & 45.44 & -0.42 & -0.55 & 0.09 & 16.45 \\
\hline \multicolumn{10}{|c|}{$6 \mathrm{x}$ case, $\mathrm{BAU}$} \\
\hline 2017 & 22.29 & 9.41 & 11.67 & 28.73 & 10.58 & -0.26 & -0.22 & 0.09 & 6.12 \\
\hline 2025 & 24.71 & 10.84 & 13.42 & 33.96 & 12.24 & -0.25 & -0.22 & 0.10 & 6.77 \\
\hline 2050 & 31.90 & 16.04 & 20.20 & 53.98 & 17.04 & -0.22 & -0.21 & 0.12 & 8.28 \\
\hline 2100 & 80.96 & 47.67 & 64.47 & 178.62 & 43.24 & -0.33 & -0.31 & 0.26 & 17.54 \\
\hline \multicolumn{10}{|c|}{ 6x case, optimal } \\
\hline 2017 & 17.63 & 5.81 & 8.48 & 19.06 & 10.19 & -0.25 & -0.25 & 0.06 & 5.99 \\
\hline 2025 & 18.82 & 6.29 & 9.39 & 21.85 & 11.80 & -0.24 & -0.26 & 0.06 & 6.63 \\
\hline 2050 & 22.93 & 8.38 & 13.64 & 34.58 & 17.97 & -0.24 & -0.29 & 0.07 & 8.62 \\
\hline 2100 & 49.15 & 21.31 & 42.97 & $\begin{array}{r}118.96 \\
42\end{array}$ & 50.48 & -0.42 & -0.55 & 0.12 & 18.93 \\
\hline
\end{tabular}


Table 9: Social Cost of carbon, $\$$ per Ton of CO2, Part 2

BRA MEX SAF MENA SLA SSA SOV GBR ANZ Global $1 \mathrm{x}$ case, BAU

\begin{tabular}{|c|c|c|c|c|c|c|c|c|c|c|}
\hline 2017 & 0.76 & 0.28 & 0.10 & 2.47 & 0.60 & 0.86 & 0.06 & 0.08 & 0.37 & 22.84 \\
\hline 2025 & 0.83 & 0.29 & 0.11 & 2.86 & 0.63 & 1.03 & 0.07 & 0.09 & 0.42 & 27.03 \\
\hline 2050 & 0.90 & 0.29 & 0.13 & 3.79 & 0.63 & 1.55 & 0.11 & 0.15 & 0.56 & 40.15 \\
\hline 2100 & 1.67 & 0.41 & 0.25 & 8.02 & 0.91 & 4.03 & 0.30 & 0.46 & 1.43 & 116.84 \\
\hline \multicolumn{11}{|c|}{ 1x case, optimal } \\
\hline 2017 & 0.80 & 0.28 & 0.09 & 2.50 & 0.62 & 0.90 & 0.04 & 0.06 & 0.37 & 22.41 \\
\hline 2025 & 0.87 & 0.30 & 0.11 & 2.91 & 0.66 & 1.08 & 0.05 & 0.07 & 0.42 & 26.48 \\
\hline 2050 & 1.00 & 0.31 & 0.13 & 3.97 & 0.69 & 1.67 & 0.08 & 0.11 & 0.56 & 39.90 \\
\hline 2100 & 1.95 & 0.44 & 0.24 & 8.42 & 1.05 & 4.44 & 0.23 & 0.32 & 1.42 & 118.62 \\
\hline \multicolumn{11}{|c|}{$2 \mathrm{x}$ case, $\mathrm{BAU}$} \\
\hline 2017 & 1.41 & 0.53 & 0.19 & 4.52 & 1.12 & 1.55 & 0.11 & 0.16 & 0.72 & 43.88 \\
\hline 2025 & 1.52 & 0.56 & 0.21 & 5.20 & 1.18 & 1.84 & 0.14 & 0.19 & 0.82 & 51.43 \\
\hline 2050 & 1.61 & 0.55 & 0.25 & 6.72 & 1.15 & 2.70 & 0.22 & 0.31 & 1.08 & 75.04 \\
\hline 2100 & 2.92 & 0.75 & 0.46 & 13.82 & 1.64 & 6.85 & 0.60 & 0.93 & 2.72 & 215.00 \\
\hline \multicolumn{11}{|c|}{$2 \mathrm{x}$ case, optimal } \\
\hline 2017 & 1.43 & 0.52 & 0.17 & 4.34 & 1.13 & 1.52 & 0.08 & 0.11 & 0.67 & 39.28 \\
\hline 2025 & 1.54 & 0.55 & 0.19 & 4.96 & 1.19 & 1.80 & 0.09 & 0.12 & 0.74 & 45.45 \\
\hline 2050 & 1.69 & 0.54 & 0.22 & 6.48 & 1.19 & 2.68 & 0.13 & 0.18 & 0.96 & 65.49 \\
\hline 2100 & 2.99 & 0.69 & 0.37 & 12.43 & 1.64 & 6.47 & 0.34 & 0.46 & 2.20 & 182.00 \\
\hline \multicolumn{11}{|c|}{$4 \mathrm{x}$ case, $\mathrm{BAU}$} \\
\hline 2017 & 2.42 & 0.98 & 0.35 & 7.63 & 1.98 & 2.54 & 0.23 & 0.33 & 1.39 & 80.64 \\
\hline 2025 & 2.55 & 1.02 & 0.39 & 8.59 & 2.05 & 2.96 & 0.28 & 0.40 & 1.55 & 92.94 \\
\hline 2050 & 2.59 & 0.96 & 0.45 & 10.64 & 1.93 & 4.17 & 0.44 & 0.63 & 1.99 & 132.09 \\
\hline 2100 & 4.53 & 1.28 & 0.80 & 20.89 & 2.66 & 10.12 & 1.18 & 1.86 & 4.91 & 371.09 \\
\hline \multicolumn{11}{|c|}{$4 \mathrm{x}$ case, optimal } \\
\hline 2017 & 2.44 & 0.94 & 0.30 & 7.08 & 1.96 & 2.42 & 0.13 & 0.18 & 1.20 & 66.70 \\
\hline 2025 & 2.58 & 0.97 & 0.32 & 7.91 & 2.03 & 2.80 & 0.15 & 0.20 & 1.31 & 75.19 \\
\hline 2050 & 2.73 & 0.92 & 0.36 & 9.98 & 1.99 & 4.04 & 0.21 & 0.28 & 1.61 & 104.63 \\
\hline 2100 & 4.50 & 1.10 & 0.58 & 17.99 & 2.54 & 9.10 & 0.54 & 0.69 & 3.46 & 280.05 \\
\hline \multicolumn{11}{|c|}{$6 \mathrm{x}$ case, $\mathrm{BAU}$} \\
\hline 2017 & 3.12 & 1.35 & 0.49 & 9.69 & 2.63 & 3.14 & 0.36 & 0.52 & 1.98 & 111.69 \\
\hline 2025 & 3.22 & 1.39 & 0.54 & 10.70 & 2.68 & 3.59 & 0.43 & 0.62 & 2.18 & 126.89 \\
\hline 2050 & 3.16 & 1.27 & 0.60 & 12.73 & 2.43 & 4.88 & 0.66 & 0.95 & 2.75 & 176.57 \\
\hline 2100 & 5.34 & 1.66 & 1.05 & 24.13 & 3.28 & 11.45 & 1.72 & 2.77 & 6.65 & 490.15 \\
\hline \multicolumn{11}{|c|}{ 6x case, optimal } \\
\hline 2017 & 3.18 & 1.28 & 0.40 & 8.91 & 2.60 & 2.97 & 0.18 & 0.25 & 1.66 & 88.16 \\
\hline 2025 & 3.30 & 1.30 & 0.42 & 9.77 & 2.65 & 3.38 & 0.20 & 0.28 & 1.77 & 97.40 \\
\hline 2050 & 3.41 & 1.21 & 0.47 & 12.06 & 2.57 & 4.79 & 0.28 & 0.37 & 2.14 & 132.95 \\
\hline 2100 & 5.36 & 1.39 & 0.74 & 21.27 & 3.12 & 10.41 & 0.71 & 0.88 & 4.42 & 349.26 \\
\hline
\end{tabular}



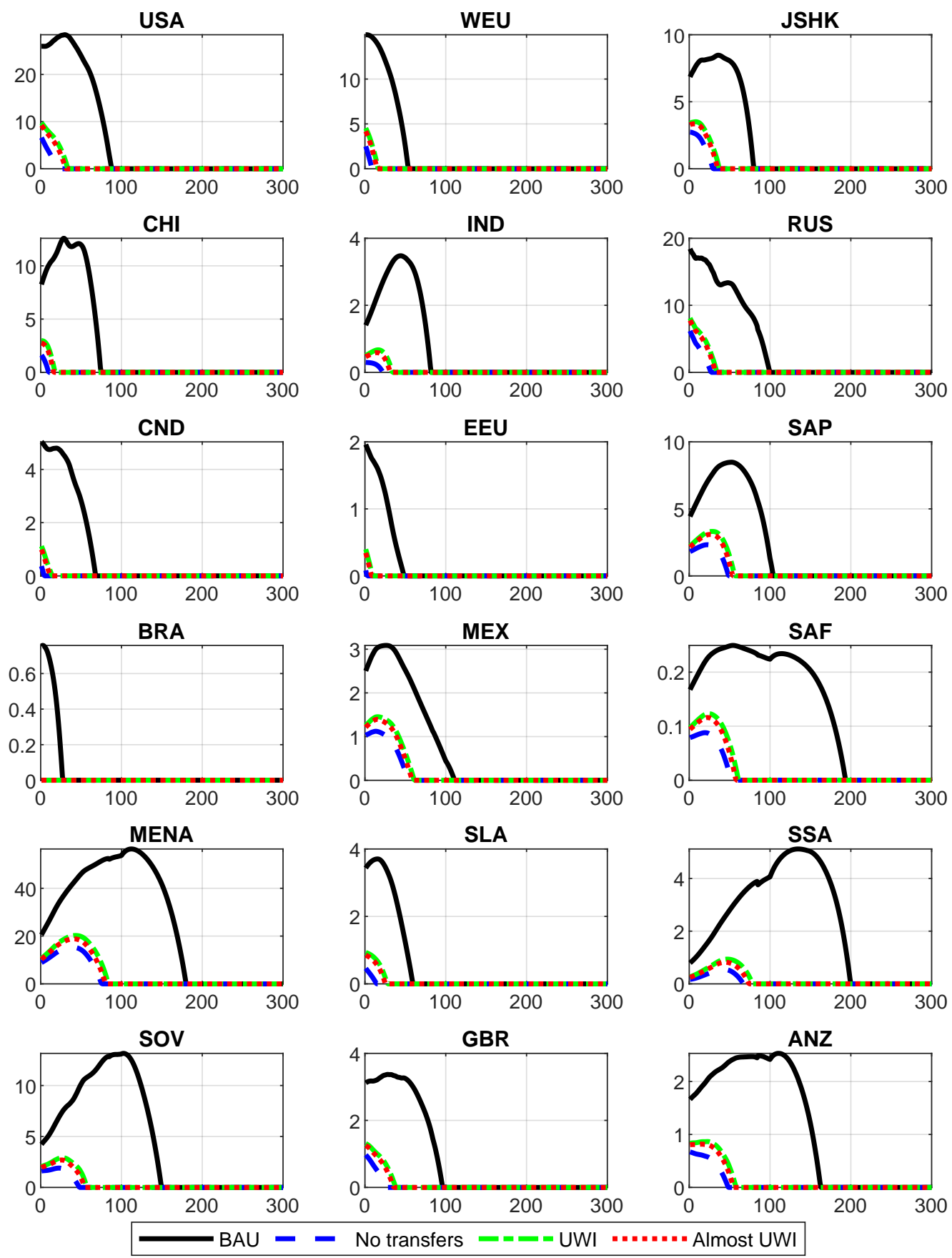

Figure 14: Gas consumption in the 6x case (measured in quad Btu) 

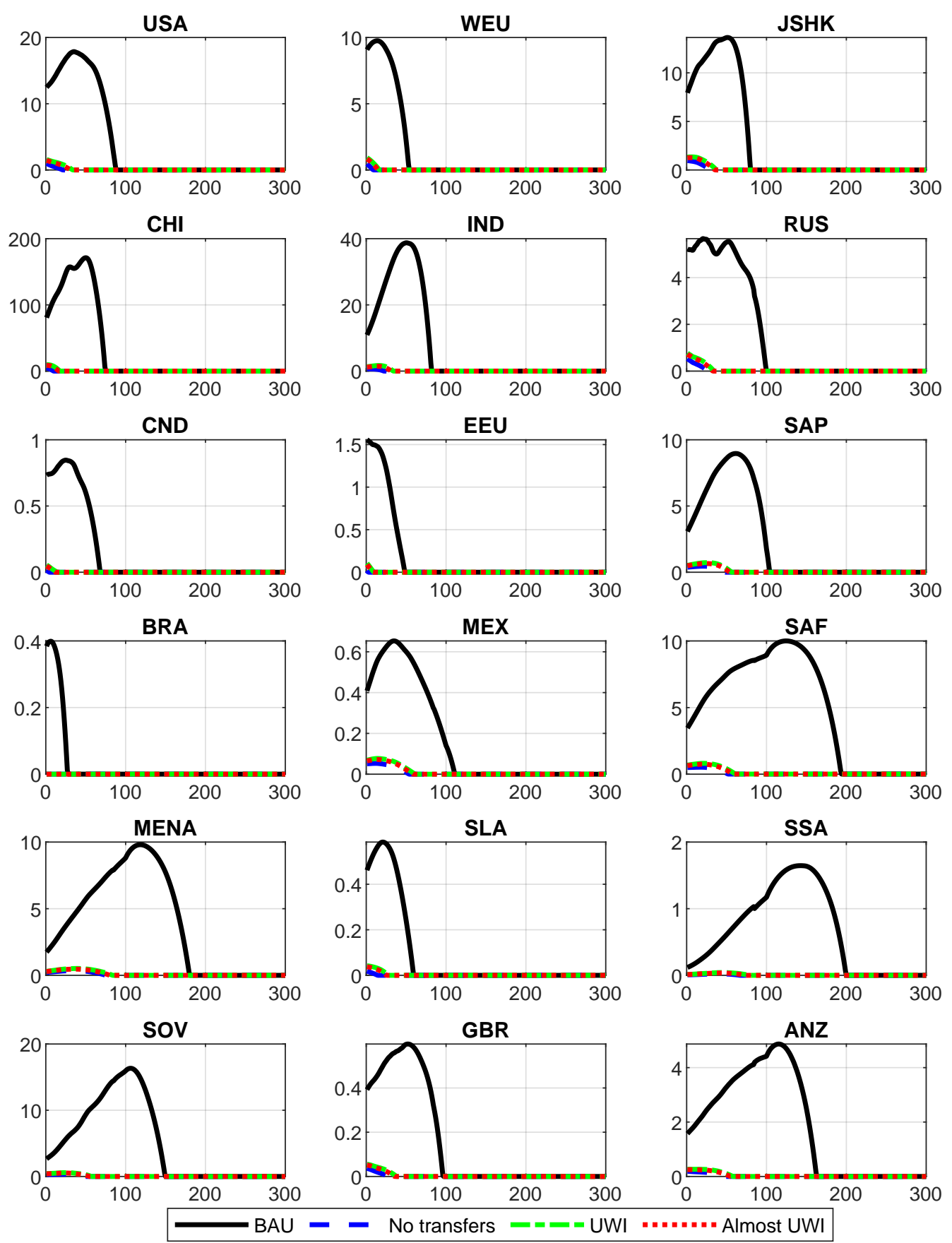

Figure 15: Coal consumption in the 6x case (measured in quad Btu) 
Table 10: Regional GDP as a Share of World GDP in the 6x scenario.

\begin{tabular}{l|cc|cc|cc|cc} 
& \multicolumn{2}{|c|}{2017 year } & \multicolumn{2}{c|}{2050 year } & \multicolumn{2}{c|}{2100 year } & \multicolumn{2}{c}{2150 year } \\
\hline & BAU & Optimal & BAU & Optimal & BAU & Optimal & BAU & Optimal \\
US & 25.01 & 25.43 & 22.04 & 22.22 & 15.55 & 15.54 & 14.89 & 14.84 \\
WEU & 21.98 & 22.45 & 18.69 & 18.78 & 17.11 & 16.16 & 16.84 & 15.61 \\
JSHK & 9.05 & 9.20 & 9.37 & 9.36 & 12.34 & 12.30 & 13.63 & 13.48 \\
CHI & 15.59 & 14.92 & 20.56 & 20.03 & 32.61 & 32.69 & 35.54 & 35.47 \\
IND & 2.59 & 2.49 & 4.60 & 4.73 & 5.38 & 6.43 & 5.00 & 6.16 \\
RUS & 2.30 & 2.10 & 1.34 & 1.12 & 0.84 & 0.72 & 0.70 & 0.60 \\
CND & 2.37 & 2.33 & 2.02 & 1.94 & 1.49 & 1.34 & 1.44 & 1.25 \\
EEU & 0.35 & 0.31 & 0.19 & 0.18 & 0.10 & 0.10 & 0.08 & 0.08 \\
SAP & 2.60 & 2.60 & 3.28 & 3.43 & 2.73 & 3.03 & 2.26 & 2.63 \\
BRA & 2.24 & 2.27 & 1.84 & 2.02 & 0.93 & 1.04 & 0.70 & 0.79 \\
MEX & 1.39 & 1.40 & 1.12 & 1.14 & 0.39 & 0.40 & 0.25 & 0.26 \\
SAF & 0.42 & 0.39 & 0.42 & 0.38 & 0.23 & 0.20 & 0.16 & 0.15 \\
MENA & 4.53 & 4.41 & 5.51 & 5.58 & 3.83 & 3.74 & 2.85 & 3.05 \\
SLA & 2.36 & 2.36 & 1.83 & 1.90 & 0.70 & 0.76 & 0.46 & 0.50 \\
SSA & 1.05 & 1.07 & 1.62 & 1.73 & 1.51 & 1.64 & 1.37 & 1.55 \\
SOV & 0.50 & 0.44 & 0.63 & 0.52 & 0.60 & 0.47 & 0.46 & 0.42 \\
GBR & 3.74 & 3.86 & 3.20 & 3.15 & 2.41 & 2.20 & 2.24 & 2.00 \\
ANZ & 1.91 & 1.96 & 1.75 & 1.78 & 1.26 & 1.24 & 1.16 & 1.16 \\
\hline
\end{tabular}




\section{A.4 Solution Method}

This section details our solution algorithm, which recursively solves a series of simple one-period problems. This technique can be applied in more complex, multi-sector OLG trade models. We also use an iterative procedure to find the optimal carbon-tax path, updating each period's carbon tax to that period's SCC in each iteration.

We first describe our five-step algorithm conditional on a given tax path.

- Step 1.1: Set a high value of $\bar{t}$, in our case, 1000 to provide sufficient time for atmospheric CO2 to stabilize, permitting the economy to reach its steady-state. Also guess the time paths of the aggregate capital stock, oil, coal, and gas reserves, and region-specific total factor productivities.

- Step 1.2: Next, use backward induction for $t=\bar{t}-1, . ., 1$ to solve the nonlinear system of equations (1)-(9), (11)-(16), (24)-(26), and (32)-(35). Their solutions provide region-specific final output paths, $Y_{z, t}$, region-specific final-output factor demands for capital, $K_{z, y, t}$, labor, $L_{z, y, t}$, and energy, $E_{z, t}$, the world interest-rate path, $r_{t}$, region-specific paths of wages, $w_{z, t}$, region-specific paths of energy prices, $p_{z, t}$, region-specific clean-energy output paths, $S_{z, t}$, region-specific clean-energy factordemand paths for capital, $K_{z, s, t}$, and labor, $L_{z, s, t}$, region-specific land rental price paths, $n_{z, t}$, region-specific usage paths of dirty energy, $E_{z, t}^{D}$, oil, $O_{z, t}$, gas, $G_{z, t}$, and coal, $\mathcal{C}_{z, t}$, region-specific dirty energy prices, $p_{z, t}^{D}$, regions-specific paths of the Lagrange multiplier governing dirty energy usage, $\chi_{z, t}$, paths of global extraction of oil, $O_{t}$, gas, $G_{t}$, and coal, $\mathcal{C}_{t}$, paths of global prices for oil, $p_{t}^{O}$, gas, $p_{t}^{G}$, and coal, $p_{t}^{\mathcal{C}}$, the path of Lagrange multipliers governing extraction of the dirty-energy reserves (21), $\ell_{t}^{O}, \ell_{t}^{G}, \ell_{t}^{\mathcal{C}}$, paths of Lagrange multipliers restricting dirty-energy extraction to be positive (23), $\mu_{t}^{O}, \mu_{t}^{G}, \mu_{t}^{\mathcal{C}}$ with given regional productivity in final output, $A_{z, t}$, and clean energy, $B_{z, t}$, production sectors, regional land supply, $H_{z, t}$, regional labor supply, $L_{z, t}$, world capital supply, $K_{t}$, reserves of oil, $R_{t}^{O}$, gas, $R_{t}^{G}$, and coal, $R_{t}^{\mathcal{C}}$, and next-period Lagrange multipliers for dirty energy reserves extraction dynamics (21), $\ell_{t+1}^{O}, \ell_{t+1}^{G}, \ell_{t+1}^{\mathcal{C}}$.

The Lagrange multipliers, $\psi_{t}^{O}, \psi_{t}^{G}$ and $\psi_{t}^{\mathcal{C}}$, ensuring the non-negativity of dirtyenergy reserves (see (22), are never binding and, thus, set to zero. Finally, the terminal values of the Lagrange multipliers for dirty-energy reserves dynamics are set equal to zero, $\ell_{\bar{t}}^{O}, \ell_{\bar{t}}^{G}, \ell_{\bar{t}}^{\mathcal{C}}$. Thus, for each point in time, $t$, we solve a system of 301 equations for 301 variables.

- Step 1.3) Use the above-referenced trial solution paths to determine the regionspecific time paths of households' aggregate supplies of capital. From the paths of oil, gas, and coal extraction, we also determine the global time paths of dirty energy reserves, climate variables, damages, and region-specific productivity.

- Step 1.4) Update guessed time paths of the aggregate capital stock, oil, coal, and gas reserves, and region-specific productivity paths.

- Step 1.5) Iterate on steps 1.2-1.4 until convergence. 
Next, consider solving the model for a given carbon-tax path (the zero-tax scenario is equivalent to the BAU scenario) combined with the use of the Auerbach and Kotlikoff (1987) Lump-Sum Redistribution Authority (LSRA), which can implement pre-specified Pareto-efficient outcomes. We first use the LSRA by Auerbach and Kotlikoff (1987) to derive the largest UWI carbon-tax policy, where welfare changes are measured as compensating consumption differentials, that is, $\lambda$.

- Step 2.1: Guess $\lambda$.

- Step 2.2: Given the guessed $\lambda$, iterate on steps 1.2-1.4, including updating transfers to ensure uniform welfare gains increase.

- Step 2.3: Calculate a present value of the transfers. If it is positive, decrease $\lambda$. If it is negative, increase $\lambda$.

- Step 2.4: Iterate on steps 2.2-2.3 until the present value of transfers approaches zero.

We determine the optimal global carbon-tax rate path numerically as follows:

- Step 3.1: Guess the time path of the optimal carbon tax based on the time path of the SCC (social costs of carbon) in the BAU scenario.

- Step 3.2: For a given tax path find LSRA solution (Steps 2.1-2.4).

- Step 3.3: Calculate the new equilibrium SCC path. Update the guessed path of the optimal carbon tax based on the new SCC path.

- Step 3.4: Iterate 3.2-3.3 until convergence.

\section{References}

Andrew Abel and Laurence J Kotlikoff. Intergenerational altruism and the effectiveness of fiscal policy: New tests based on cohort data. Savings and bequests, pages 31-42, 1994.

Daron Acemoglu, Philippe Aghion, Leonardo Bursztyn, and David Hemous. The environment and directed technical change. American economic review, 102(1):131-66, 2012.

Joseph G Altonji, Fumio Hayashi, and Laurence J Kotlikoff. Is the extended family altruistically linked? direct tests using micro data. The American Economic Review, pages 1177-1198, 1992.

Joseph G Altonji, Fumio Hayashi, and Laurence J Kotlikoff. Parental altruism and inter vivos transfers: Theory and evidence. Journal of political economy, 105(6):1121-1166, 1997. 
Alberto Ansuategi and Marta Escapa. Economic growth and greenhouse gas emissions. Ecological Economics, 40(1):23-37, 2002. ISSN 09218009. doi: 10.1016/S0921-8009(01)00272-5.

Alan J Auerbach and Laurence J Kotlikoff. Dynamic fiscal policy. Cambridge University Press, 1987.

Raymond G Batina and Jeffrey a Krautkraemer. On sustainability and intergenerational transfers with a renewable resource. Land Economics, 75(2):167-184, 1999.

Seth G Benzell, Laurence J Kotlikoff, and Guillermo LaGarda. Simulating business cash flow taxation: An illustration based on the 'better way' corporate tax reform. Technical report, National Bureau of Economic Research, 2017.

B Douglas Bernheim and Kyle Bagwell. Is everything neutral? Journal of Political Economy, 96(2):308-338, 1988.

Valentina Bosetti, Cristina Cattaneo, and Giovanni Peri. Should they stay or should they go? Climate migrants and local conflicts. Journal of Economic Geography, 21(4):619-651, 022020. ISSN 1468-2702. doi: 10.1093/jeg/lbaa002. URL https://doi .org/10.1093/jeg/lbaa002.

A. Lans Bovenberg and Ben J. Heijdra. Environmental abatement and intergenerational distribution. Environmental and Resource Economics, 23(1):45-84, 2002. ISSN 09246460. doi: 10.1023/A:1020236812676.

A.Lans Bovenberg and Ben J Heijdra. Environmental tax policy and intergenerational distribution. Journal of Public Economics, 67(1):1-24, 1998. ISSN 00472727. doi: 10.1016/S00472727(97)00064-9.

Peter S. Burton. Intertemporal preferences and intergenerational equity considerations in optimal resource harvesting. Journal of Environmental Economics and Management, 24(2):119132, 1993. ISSN 0095-0696. doi: 10.1006/jeem.1993.1008. URL http://www . sciencedirect. com/science/article/B6WJ6-45P13FR-1D/2/3df3a733c83612ef9a6056ec25a0c47c.

Guillermo A. Calvo and Maurice Obstfeld. Optimal time-consistent fiscal policy with finite lifetimes. Econometrica, 56(2):411-432, 1988.

David Castells-Quintana, Melanie Krause, and Thomas K J McDermott. The urbanising force of global warming: the role of climate change in the spatial distribution of population. Journal of Economic Geography, 21(4):531-556, 11 2020. ISSN 1468-2702. doi: 10.1093/jeg/lbaa030. URL https://doi.org/10.1093/jeg/lbaa030.

Bruno Conte, Klaus Desmet, Dávid Krisztián Nagy, and Esteban Rossi-Hansberg. Local sectoral specialization in a warming world. Journal of Economic Geography, 21(4):493-530, 092021. ISSN 1468-2702. doi: 10.1093/jeg/lbab008. URL https://doi .org/10.1093/jeg/lbab008.

Jose-Luis Cruz and Esteban Rossi-Hansberg. The Economic Geography of Global Warming. 2021. 
Simon Dietz, Frederick van der Ploeg, Armon Rezai, and Frank Venmans. Are economists getting climate dynamics right and does it matter? Journal of the Association of Environmental and Resource Economists, 8(5):895-921, 2021. doi: 10.1086/713977. URL https://doi.org/10.1086/713977.

Jonathan Eaton and Raquel Fernandez. Sovereign debt. Handbook of international economics, 3:2031-2077, 1995.

Lee H. Endress, Sittidaj Pongkijvorasin, James Roumasset, and Christopher A. Wada. Intergenerational equity with individual impatience in a model of optimal and sustainable growth. Resource and Energy Economics, 36(2):620-635, 2014. ISSN 09287655. doi: 10.1016/ j.reseneeco.2013.10.001. URL http://dx.doi.org/10.1016/j.reseneeco.2013.10.001.

Doris Folini, Felix Kubler, Aleksandra Malova, and Simon Scheidegger. The climate in climate economics. Available at SSRN 3885021, 2021.

Olivier Geoffroy, D. Saint-Martin, G. Bellon, A. Voldoire, D. J.L. Olivié, and S. Tytéca. Transient climate response in a two-layer energy-balance model. Part II: Representation of the efficacy of deep-ocean heat uptake and validation for CMIP5 AOGCMs. Journal of Climate, 26(6):1859-1876, 2013. ISSN 08948755. doi: 10.1175/JCLI-D-12-00196.1.

Reyer Gerlagh and Michiel A. Keyzer. Sustainability and the intergenerational distribution of natural resource entitlements. Journal of Public Economics, 79(2):315-341, 2001. ISSN 00472727. doi: 10.1016/S0047-2727(99)00122-X.

Reyer Gerlagh and B.C.C. van der Zwaan. The effects of ageing and an environmental trust fund in an overlapping generations model on carbon emission reductions. Ecological Economics, 36(2):311-326, 2001. ISSN 09218009. doi: 10.1016/S0921-8009(00)00232-9.

Jagadeesh Gokhale, Laurence J Kotlikoff, and John Sabelhaus. Understanding the postwar decline in us saving: A cohort analysis. brookings papers on economic activity. ed. w. brainard and g. perry. washington dc: Brookings institution. 1996.

Mikhail Golosov, John Hassler, Per Krusell, and Aleh Tsyvinski. Optimal taxes on fossil fuel in general equilibrium. Econometrica, 82(1):41-88, 2014.

Lawrence H Goulder. Environmental taxation and the double dividend: a reader's guide. International tax and public finance, 2(2):157-183, 1995.

Michael Grimm. Rainfall risk, fertility and development: evidence from farm settlements during the American demographic transition. Journal of Economic Geography, 21(4):593-618, 12 2019. ISSN 1468-2702. doi: 10.1093/jeg/lbz039. URL https://doi.org/10.1093/jeg/ $1 \mathrm{bz039}$.

Martin C. Hänsel, Moritz A. Drupp, Daniel J.A. Johansson, Frikk Nesje, Christian Azar, Mark C. Freeman, Ben Groom, and Thomas Sterner. Climate economics support for the UN climate targets. Nature Climate Change, 10(8):781-789, 2020. ISSN 17586798. doi: 10.1038/s41558-020-0833-x. URL http://dx.doi.org/10.1038/s41558-020-0833-x. 
John Hassler, Per Krusell, and Conny Olovsson. Energy-saving technical change. Technical report, National Bureau of Economic Research, 2012.

John Hassler, Per Krusell, Conny Olovsson, and Michael Reiter. On the effectiveness of climate policies. Technical report, 2020.

Zeke Hausfather and Glen P Peters. Emissions-the 'business as usual'story is misleading, 2020.

Fumio Hayashi, Joseph Altonji, and Laurence Kotlikoff. Risk-sharing between and within families. Econometrica, 64(2):261-294, 1996.

Ben J. Heijdra, Jan Peter Kooiman, and Jenny E. Ligthart. Environmental quality, the macroeconomy, and intergenerational distribution. Resource and Energy Economics, 28(1):74-104, 2006. ISSN 09287655. doi: 10.1016/j.reseneeco.2005.05.001.

Elmar Hillebrand and Marten Hillebrand. Who pays the bill? climate change, taxes, and transfers in a multi-region growth model. Technical report, 2020.

Harold Hotelling. The economics of exhaustible resources. The journal of political economy, pages 137-175, 1931.

Peter H. Howard and Thomas Sterner. Few and Not So Far Between: A Meta-analysis of Climate Damage Estimates. Environmental and Resource Economics, 68(1):197-225, 2017. ISSN 15731502. doi: 10.1007/s10640-017-0166-z.

Richard B. Howarth. Intertemporal equilibria and exhaustible resources: an overlapping generations approach. Ecological Economics, 4(3):237-252, 1991a. ISSN 09218009. doi: 10.1016/0921-8009(91)90053-H.

Richard B. Howarth. Intergenerational competitive equilibria under technological uncertainty and an exhaustible resource constraint. Journal of Environmental Economics and Management, 21(3):225-243, 1991b. ISSN 10960449. doi: 10.1016/0095-0696(91)90028-H.

Richard B. Howarth. An overlapping generations model of climate-economy interactions. The Scandinavian Journal of Economics, 100(3):575-591, 1998.

Richard B. Howarth and Richard B. Norgaard. Intergenerational resource rights, efficiency, and social optimality. Land Economics, 66(1):1-11, 1990. ISSN 00987484. doi: 10.1186/14787547-10-9.

Richard B Howarth and Richard B Norgaard. Environmental valuation under sustainable development. American Economic Review, 82(2):473-477, 1992. ISSN 00028282. doi: 10. $1002 /$ sd.181.

Agustín Indaco, Francesc Ortega, Taṣpinar, and Süleyman. Hurricanes, flood risk and the economic adaptation of businesses. Journal of Economic Geography, 21(4):557-591, 112020. ISSN 1468-2702. doi: 10.1093/jeg/lbaa020. URL https://doi .org/10.1093/jeg/lbaa020.

A. John, R. Pecchenino, D. Schimmelpfennig, and S. Schreft. Short-lived agents and the longlived environment. Journal of Public Economics, 58(1):127-141, 1995. ISSN 00472727. doi: 10.1016/0047-2727(94)01459-2. 
Larry Karp and Armon Rezai. The political economy of environmental policy with overlapping generations. International Economy Review, 55(3):711-733, 2014.

Anna A. Klis and Matthew McGinty. Citizen carbon fund: Harmonized international carbon taxes and transfers to increase treaty size. The B.E. Journal of Economic Analysis Policy, 2022. doi: doi:10.1515/bejeap-2021-0072. URL https://doi.org/10.1515/bejeap-20210072 .

Laurence Kotlikoff, Felix Kubler, Andrey Polbin, Jeffrey Sachs, and Simon Scheidegger. Making Carbon Taxation a Generational Win Win. International Economic Review, 62(1):3-46, 2021. ISSN 1468-2354. doi: 10.1111/iere.12483.

Laurence J Kotlikoff. Altruistic linkages within the extended family, a note. Sloan Foundation Proposal, 1983.

B. Kravitz, C. Lynch, C. Hartin, and B. Bond-Lamberty. Exploring precipitation pattern scaling methodologies and robustness among cmip5 models. Geoscientific Model Development, 10 (5):1889-1902, 2017. doi: 10.5194/gmd-10-1889-2017. URL https ://gmd . copernicus .org/ articles/10/1889/2017/

Per Krusell and Tony Smith. Climate change around the world. Technical report, 2018.

Per Krusell and Anthony A Smith Jr. Climate change around the world. 2018. URL http: //www.econ.yale.edu/smith/munich2.pdf

R. Link, A. Snyder, C. Lynch, C. Hartin, B. Kravitz, and B. Bond-Lamberty. Fldgen v1.0: an emulator with internal variability and space-time correlation for earth system models. Geoscientific Model Development, 12(4):1477-1489, 2019. doi: 10.5194/gmd-12-1477-2019. URL https://gmd. copernicus .org/articles/12/1477/2019/.

Oleg Lugovoy and Andrey Polbin. On intergenerational equity of greenhouse gases emissions abatement. The Journal of the New Economic Association, 31(3), 2016.

C. Lynch, C. Hartin, B. Bond-Lamberty, and B. Kravitz. An open-access cmip5 pattern library for temperature and precipitation: description and methodology. Earth System Science Data, 9(1):281-292, 2017. doi: 10.5194/essd-9-281-2017. URL https://essd.copernicus.org/ articles/9/281/2017/.

Giancarlo Marini and Pasquale Scaramozzino. Overlapping generations and environmental control. Journal of Environmental Economics and Management, 29(1):64-77, 1995. URL http://www.sciencedirect.com/science/article/pii/S0095069685710315\$ backslash\$npapers2://publication/uuid/E5065B74-2BDF-4783-81AE-6062A3C0D8CB

Christophe McGlade and Paul Ekins. The geographical distribution of fossil fuels unused when limiting global warming to 2 c. Nature, 517(7533):187, 2015.

M. Meinshausen, T. M. L. Wigley, and S. C. B. Raper. Emulating atmosphere-ocean and carbon cycle models with a simpler model, MAGICC6 - Part 2: Applications. Atmospheric Chemistry $\&$ Physics, 11:1457-1471, February 2011. doi: 10.5194/acp-11-1457-2011. 
Alex Mourmouras. Competitive equilibria and sustainable growth in a life-cycle model with natural resources. The Scandinavian Journal of Economics, 93(4):585591, 1991. URL http://links.jstor.org/sici?sici=0347-0520(199112)93:4\{\T2A\ textless\}585: CEASGI $\{\backslash$ T2A \textgreater\}2.0.C0;2-L.

Alex Mourmouras. Conservationist government policies and intergenerational equity in an overlapping generations model with renewable resources. Journal of Public Economics, 51 (2):249-268, 1993. ISSN 00472727. doi: 10.1016/0047-2727(93)90088-B.

Ulrich K Müller, James H Stock, and Mark W Watson. An econometric model of international long-run growth dynamics. Technical report, National Bureau of Economic Research, 2019.

William D. Nordhaus. The efficient use of energy resources / William D. Nordhaus. Monograph - Cowles Foundation for Research in Economics at Yale University ; 26. Yale University Press, New Haven, 1979.

William D Nordhaus. A Question of Balance: Weighing the Options on Global Warming Policies. Yale University Press, New Haven, CT, 2008.

William D Nordhaus. Economic aspects of global warming in a post-copenhagen environment. Proceedings of the National Academy of Sciences, 107(26):11721-11726, 2010.

William D Nordhaus. Climate clubs: overcoming free-riding in international climate policy. The American Economic Review, 105(4):1339-1370, 2015.

William D. Nordhaus. Revisiting the social cost of carbon. Proceedings of the National Academy of Sciences of the United States of America, 114(7):1518-1523, 2017. ISSN 10916490. doi: $10.1073 /$ pnas.1609244114.

William D Nordhaus and Zili Yang. A regional dynamic general-equilibrium model of alternative climate-change strategies. The American Economic Review, pages 741-765, 1996.

$\mathrm{R}$ Pecchenino and A. John. An overlapping generations model of growth and the environment. The Economic Journal, 104(427):1393-1410, 1994.

Giovanni Peri and Frédéric Robert-Nicoud. On the economic geography of climate change. Journal of Economic Geography, 21(4):487-491, 10 2021. ISSN 1468-2702. doi: 10.1093/jeg/ lbab027. URL https://doi.org/10.1093/jeg/lbab027.

Arthur C Pigou. Wealth and welfare, london, 1912. Later editions, The Eco $\neg$ nomics of Welfare, 1920.

Robert S Pindyck. Climate change policy: what do the models tell us? Journal of Economic Literature, 51(3):860-72, 2013.

Tobias N. Rasmussen. Modeling the economics of greenhouse gas abatement: an overlapping generations perspective. Review of Economic Dynamics, 6(1):99-119, 2003. ISSN 10942025. doi: 10.1016/S1094-2025(02)00010-8. 
B. D. Santer, T. M. L Wigley, M. E. Schlesinger, and J. F. B. Mitchell. Developing climate scenarios from equilibrium gcm results. Technical report, Tech. Rep., Max-Planck-Institut fuer Meteorologie, Hamburg, Germany, 1990.

Maik T. Schneider, Christian P. Traeger, and Ralph Winkler. Trading off generations: equity, discounting, and climate change. European Economic Review, 56(8):1621-1644, 2012. ISSN 00142921. doi: 10.1016/j.euroecorev.2012.08.006. URL http://dx.doi.org/10.1016/j. euroecorev.2012.08.006.

Hans-Werner Sinn. The green paradox. In CESifo forum, volume 10, pages 10-13. München: ifo Institut für Wirtschaftsforschung an der Universität München, 2009.

HW Sinn. Absatzsteuern, ölförderung und das allmendeproblem. Reaktionen auf Energiepreissteigerungen, Frankfurt: Lang, pages 83-103, 1982.

Robert M Solow. The economics of resources or the resources of economics. The American Economic Review, 64(2):1-14, 1974a.

Robert M Solow. Intergenerational equity and exhaustible resources. The Review of Economic Studies, 41:29-45, 1974b.

Karl E. Taylor, Ronald J. Stouffer, and Gerald A. Meehl. An Overview of CMIP5 and the Experiment Design. Bull. Amer. Meteor. Soc., 93:485-498, 2012. doi: 10.1175/BAMS-D-1100094.1.

Claudia Tebaldi and Julie Arblaster. Pattern scaling: Its strengths and limitations, and an update on the latest model simulations. Climatic Change, 122(3):459-471, February 2014. doi: 10.1007/s10584-013-1032-9. URL https://ideas.repec.org/a/spr/climat/ v122y2014i3p459-471.html.

United Nations. World Fertility Prospects. UN, 2019a. URL https://esa.un.org/unpd/wpp.

United Nations. World Population Prospects 2019. UN, 2019b.

Ronald Wendner. An applied dynamic general equilibrium model of environmental tax reforms and pension policy. Journal of Policy Modeling, 23(1):25-50, 2001. ISSN 01618938. doi: 10.1016/S0161-8938(00)00025-9. 